Delft University of Technology

\title{
A macroelement framework for shallow foundations including changes in configuration
}

Pisanò, F; Flessati, L; di Prisco, C

DOI

10.1680/jgeot.16.P.014

Publication date

2016

Document Version

Final published version

Published in

Géotechnique

\section{Citation (APA)}

Pisanò, F., Flessati, L., \& di Prisco, C. (2016). A macroelement framework for shallow foundations including changes in configuration. Géotechnique, 66(11), 910-926. https://doi.org/10.1680/jgeot.16.P.014

\section{Important note}

To cite this publication, please use the final published version (if applicable).

Please check the document version above.

\section{Copyright}

Other than for strictly personal use, it is not permitted to download, forward or distribute the text or part of it, without the consent of the author(s) and/or copyright holder(s), unless the work is under an open content license such as Creative Commons.

\section{Takedown policy}

Please contact us and provide details if you believe this document breaches copyrights.

We will remove access to the work immediately and investigate your claim. 


\title{
A macroelement framework for shallow foundations including changes in configuration
}

\author{
F. PISANÒ* ${ }^{*}$ L. FLESSATI $\dagger$ and C. DI PRISCO $\dagger$
}

\begin{abstract}
Macroelement plasticity models are being increasingly applied to study non-linear soil-foundation interaction (SFI) problems. Macroelement models are particularly appealing from a computational standpoint, as they can capture the essence of SFI by means of a few degrees of freedom. However, all the macroelement formulations available in the literature suffer from the same limitation, that is the incapability of accounting for changes in both geometry and loading/boundary conditions. Accordingly, macroelement models are usually calibrated to analyse a given boundary value problem, with no chance of handling situations with significant variations in embedment, lateral surcharge and/or phreatic level. The present work shows how standard soil modelling concepts can be exploited to reproduce relevant 'configurational features' of non-linear SFI. A macroelement framework is here proposed to simulate the drained load-settlement response of shallow footings on sand in the presence of varying surface/body forces. As a first step, the ideal case of a weightless soil layer is exclusively considered. The macroelement constitutive equations are conceived/calibrated on a minimal set of finite-element results; the satisfactory predictive capabilities of the macroelement model are finally demonstrated by retrospectively simulating selected finite-element tests.
\end{abstract}

KEYWORDS: bearing capacity; footings/foundations; numerical modelling; plasticity; settlement; soil/structure interaction

\section{INTRODUCTION}

In the last 25 years, force-resultant plasticity models - also termed 'macroelements' (ME) - have been gaining increasing popularity within the engineering community as a suitable tool for solving non-linear soil-foundation interaction (SFI) problems. By definition, force-resultant approaches stem from the idea of describing the global soil-foundation response by way of a single upscaled constitutive relationship, relating in the non-linear regime (a low number of) generalised force and displacement variables. When properly formulated, MEs can reproduce the mechanical response of foundations under combined loading at very low computational costs, largely lower than those needed for non-linear finite-element (FE) analyses.

Following from the earliest pioneering works (Roscoe \& Schofield, 1956; Butterfield \& Ticof, 1979; Schotmann \& Stork, 1987; Schotmann, 1989), complete elastic-plastic ME formulations for strip and circular footings were proposed by Nova \& Montrasio (1991), Montrasio \& Nova (1997) and Gottardi et al. (1999). These works brought about a paradigm shift in the study of non-linear SFI: it was acknowledged that soil specimens and foundational systems share, at different scales, many behavioural features, that can be modelled similarly. Since then, a number of ME models were developed in the plasticity framework for a very wide range of SFI problems, including, for example, offshore jack-ups and wind turbines (Martin \& Houlsby, 2001; Houlsby \& Cassidy, 2002; Byrne \& Houlsby, 2003; Nguyen-Sy, 2005; Cassidy et al., 2006; Byrne, 2013; Foglia et al., 2014;

Manuscript received 14 January 2016; revised manuscript accepted 3 May 2016. Published online ahead of print 12 July 2016.

Discussion on this paper closes on 1 April 2017, for further details see p. ii.

* Geo-Engineering Section/Offshore Engineering Section, Faculty of Civil Engineering and Geoscience, Delft University of Technology, Delft, The Netherlands.

$\dagger$ Department of Civil and Environmental Engineering, Politecnico di Milano, Milan, Italy.
Zhang et al., 2014), historical towers (Marchi et al., 2011; Pisanò et al., 2014), buried pipelines (Zhang et al., 2002; Calvetti et al., 2004; di Prisco et al., 2004; Cocchetti et al., 2008, 2009a, 2009b; Tian \& Cassidy, 2008; Cheuk \& White, 2011), rock boulders impacting granular soil layers (di Prisco \& Vecchiotti, 2006) and, lately, even piled foundations ( $\mathrm{Li}$ et al., 2015). ME formulations for cyclic/dynamic-seismic SFI problems are also available in the literature, such as those proposed by Paolucci (1997), Crémer et al. (2001, 2002), Shirato et al. (2008), Chatzigogos et al. (2009), Grange et al. (2009, 2011) and Figini et al. (2012) - the interested reader is also referred to di Prisco \& Pisanò (2011b) and di Prisco et al. (2012) for quite recent overviews on this subject.

Although the ME concept is in principle well-suited for general three-dimensional (3D) problems, most of the above works are restricted to two-dimensional (2D) verticalhorizontal-moment (VHM) loading on strip or circular footings. Only a few recent works consider fully 3D situations (Bienen et al., 2006; Grange et al., 2008, 2009; Salciarini \& Tamagnini, 2009), and even fewer also deal with torsional loading (Bienen et al., 2006; Salciarini et al., 2011; Tamagnini et al., 2013). Apart from the scarcity of fully 3D formulations, the practical employment of ME models is still encumbered by some conceptual difficulties

- the calibration of certain ME parameters usually requires specific experimental data and/or numerical (finite-element (FE)) simulations; in this sense, MEs are not fully 'self-standing'

- the interaction between closely spaced foundations (group effects) is still hardly reproducible through MEs

- only direct loads on the foundation body can be considered in ME SFI analyses.

As for the last point, it should be noted that footing deformations (and even collapse) can also be induced by variations in boundary conditions, such as changes in lateral surcharge, footing embedment and underground phreatic 
level. In practical terms, all the available ME models work by embedding site conditions into phenomenological constitutive parameters, which then do not apply to different configurations.

In the light of these premises, a novel ME framework is here proposed to include what will be henceforth termed 'configurational features'. Their role is truly two-fold, in that changes in external configuration can $(a)$ induce additional footing displacements (configurational loading, e.g. lateral excavations, subsidence, and so on) and (b) modify the global response of the footing (stiffness and strength) to following loading ('configurational set-up'). As will be clarified in the following, configurational ME models are meant to establish a new kind of 'micro-mechanical' approach to foundation analysis, in which the constitutive soil response plays within the global ME model as the micro-mechanical soil grain interaction in the formulation/calibration of phenomenological constitutive models for geomaterials.

As a first contribution on this subject, configurational features are here modelled only for vertically loaded strip footings on homogeneous sand deposits. The ideal case of weightless soil is first considered for the sake of simplicity, as was done in the past for solving simple bearing capacity problems in cohesionless materials (Chen, 2013). The paper contents are thus arranged as follows

(a) the ME framework is established by defining configuration-sensitive static/kinematic variables

(b) the results of a FE investigation are illustrated to discuss relevant configurational effects for strip footings; FE results are then exploited to conceive the new ME model

(c) the ME constitutive parameters are calibrated against a small set of FE results

(d) the ME model is finally validated against FE data not previously used for calibrating the ME parameters.

Details concerning formulation, calibration and validation of the proposed model are provided in the following sections.

\section{A CONFIGURATION-SENSITIVE ME FRAMEWORK}

Figure 1 illustrates the problem under consideration, that is, a strip footing on a homogeneous sand layer. The main assumptions introduced for ME modelling purposes are listed below.

(a) The footing breadth is equal to $B$.

(b) Purely vertical external loading is applied on the top surface. $q_{\mathrm{sf}}(x)$ is the direct load on the foundation, whereas the uniform lateral surcharge $p_{\text {sf }}$ replicates the footing embedment. It should be recalled that modelling footing embedment as a lateral surcharge is

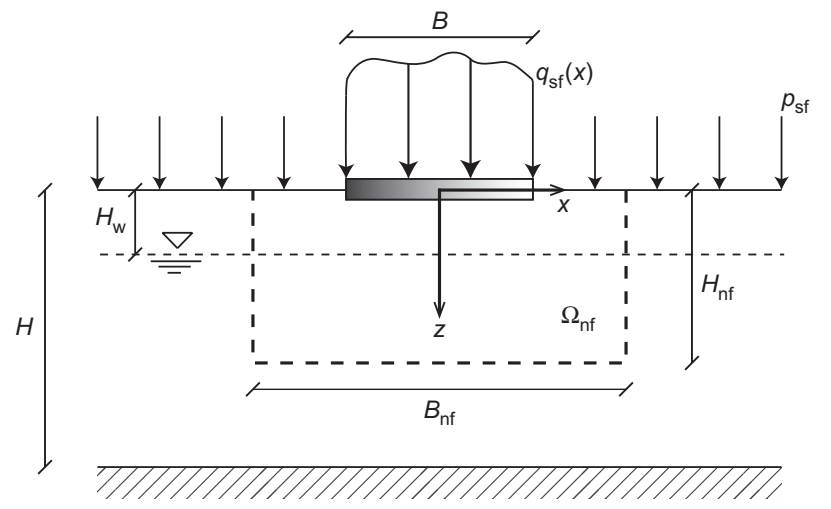

Fig. 1. Strip footing on a homogeneous sand layer only accurate for small to moderate depths (Bowles, 1996).

(c) The sand layer rests on a rigid/impervious bedrock located at depth $z=H$, while the water table is at $z=H_{\mathrm{w}}$.

(d) Sand is assumed to be highly permeable, so that drained SFI can be considered (instantaneous consolidation). Also, no steady seepage flow takes place within the soil layer.

(e) Loads are applied quasi-statically.

( $f$ ) There are no geometrical non-linearities (i.e. small displacement regime).

\section{Definition of static and kinematic variables}

In the spirit of the ME theory, foundation modelling entails an 'upscaling process' over a finite soil domain, whose mechanical response is described by way of a low number of static and kinematic variables. This process underlies the identification of a meaningful 'near-field' domain, including the soil mass mainly affecting the global SFI. Based on standard engineering idealisation, the footing response can be represented as the sum of two overlapping components, namely reversible (elastic) and unrecoverable (plastic): the former tend to take place over a large soil domain, the latter tend to concentrate over a smaller region as (shear) failure is approached.

The latter concept is illustrated in Fig. 1, where the near-field domain $\Omega_{\mathrm{nf}}$ is assumed to be represented by the following rectangular region

$$
\Omega_{\mathrm{nf}}=\left\{(x, z) \in \mathbb{R}^{2}:-\frac{B_{\mathrm{nf}}}{2} \leq x \leq \frac{B_{\mathrm{nf}}}{2} ; 0 \leq z \leq H_{\mathrm{nf}}\right\}
$$

where inequalities $B_{\mathrm{nf}} \geq B$ and $0<H_{\mathrm{nf}} \leq H$ can be intuitively anticipated. $H_{\mathrm{nf}}$ is actually likely to coincide with the layer thickness $H$, unless the gradual soil stiffening along the depth is considered (deep and stiff soil layers will negligibly contribute to the footing settlements).

The required static/kinematic ME variables are derived to ensure a proper representation of the external work input to $\Omega_{\mathrm{nf}}$ (Fig. 1), henceforth referred to as $\delta W_{\mathrm{nf}}$. Under vertical surface loads $\left(q_{\mathrm{sf}}\right.$ and $\left.p_{\mathrm{sf}}\right)$ and body forces (the soil unit weight $\gamma), \delta W_{\mathrm{nf}}$ can be computed for a virtual variation $\delta v(x, z)$ in the vertical displacement field (the term 'virtual' means a variation in vertical displacement compatible with the Dirichlet boundary conditions, i.e. in this case $\delta v(x, z=H)=0$ )

$$
\begin{gathered}
\delta W_{\mathrm{nf}}=\delta W_{\mathrm{nf}}^{\mathrm{sf}}+\delta W_{\mathrm{nf}}^{\mathrm{bd}} \\
=\underbrace{2 \int_{0}^{B / 2} q_{\mathrm{sf}}(x) \delta v(x, 0) \mathrm{d} x+2 \int_{B / 2}^{B_{n f} / 2} p_{\mathrm{sf}} \delta v(x, 0) \mathrm{d} x}_{\delta W_{\mathrm{nf}}^{\mathrm{sf}}} \\
+2 \underbrace{\int_{0}^{B_{\mathrm{nf}} / 2} \int_{0}^{H_{\mathrm{nf}}} \gamma(z) \delta v(x, z) \mathrm{d} z \mathrm{~d} x}_{\delta W_{\mathrm{nf}}^{\mathrm{bd}}}
\end{gathered}
$$

where the contributions of surface and body forces, $W_{\mathrm{nf}}^{\mathrm{sf}}$ and $W_{\mathrm{nf}}^{\mathrm{bd}}$, are distinguished. In the relevant case of $(a)$ rigid foundation $\left(v\left(|x| \leq-B_{\mathrm{nf}} / 2,0\right)\right.$ is uniform and set to an imposed, time-varying value $\bar{v}),(b)$ uniform lateral surcharge $p_{\text {sf }}$ and $(c)$ uniform soil weight $\gamma$, the following pairs of work-conjugate static and kinematic variables can reproduce the near-field external work input

$$
\delta W_{\mathrm{nf}}=\delta W_{\mathrm{nf}}^{\mathrm{sf}}+\delta W_{\mathrm{nf}}^{\mathrm{bd}}=\underbrace{V_{\mathrm{in}} \delta v_{\mathrm{in}}+V_{\mathrm{out}} \delta v_{\mathrm{out}}}_{\delta W_{\mathrm{nf}}^{\mathrm{sf}}}+\underbrace{\Gamma \delta v_{\Omega}}_{\delta W_{\mathrm{nf}}^{\mathrm{bd}}}
$$


where

$$
\begin{aligned}
& V_{\text {in }}=2 \int_{0}^{B / 2} q_{\mathrm{sf}}(x) \mathrm{d} x \Leftrightarrow \quad v_{\text {in }}=\bar{v} \\
& V_{\text {out }}=\left(B_{\mathrm{nf}}-B\right) p_{\mathrm{sf}} \Leftrightarrow v_{\mathrm{out}}=\frac{2}{B_{\mathrm{nf}}-B} \int_{B / 2}^{B_{\mathrm{nf}} / 2} v(x, 0) \mathrm{d} x \\
& \Gamma=H_{\mathrm{nf}} B_{\mathrm{nf}} \gamma \quad \Leftrightarrow v_{\Omega}=\frac{2}{B_{\mathrm{nf}} H_{\mathrm{nf}}} \int_{0}^{B_{\mathrm{nf}} / 2} \int_{0}^{H_{\mathrm{nf}}} v(x, z) \mathrm{d} z \mathrm{~d} x
\end{aligned}
$$

and $\gamma$ is either the dry or the effective unit weight when $H_{\mathrm{w}}=H$ or $H_{\mathrm{w}}=0$, respectively. (The assumption of uniform $\gamma$ is not strictly necessary, but makes explanation easier - both the expressions for $\Gamma$ and $v_{\Omega}$ should be modified in the case of non-uniform soil weight.) The above pairs of variables $\left(v_{\text {in }}-V_{\text {in }}, v_{\text {out }}-V_{\text {out }}\right.$ and $\left.v_{\Omega}-\Gamma\right)$ preserve the external work input to $\Omega_{\mathrm{nf}}$, including most of the total plastic work $\delta W^{\mathrm{p}}$ $\left(\delta W_{\mathrm{nf}}^{\mathrm{p}} \approx \delta W^{\mathrm{p}}\right)$, but only a portion of the elastic component $\delta W^{\mathrm{e}}\left(\delta W_{\mathrm{nf}}^{\mathrm{e}}\right.$ may be less than the total $\left.\delta W^{\mathrm{e}}\right)$. It will be shown in the following that an accurate description of near-field dissipation is normally enough to reproduce relevant SFI configurational features in the ME framework.

A few further manipulations on the surface work input $\delta W_{\mathrm{nf}}^{\mathrm{sf}}$ lead to the finding of two alternative pairs

$$
\delta W_{\mathrm{nf}}^{\mathrm{sf}}=V_{\mathrm{in}} \delta v_{\mathrm{in}}+V_{\mathrm{out}} \delta v_{\mathrm{out}}=P \delta v_{\mathrm{vol}}+Q \delta v_{\mathrm{dev}}
$$

based on the following definitions

$$
\begin{aligned}
& P=B_{\mathrm{nf}} \bar{\sigma}_{\mathrm{z}}=2 \int_{0}^{B / 2} q_{\mathrm{sf}}(x) \mathrm{d} x+\left(B_{\mathrm{nf}}-B\right) p_{\mathrm{sf}}=V_{\text {in }}+V_{\text {out }} \\
& v_{\mathrm{vol}}=\frac{B v_{\mathrm{in}}+\left(B_{\mathrm{nf}}-B\right) v_{\mathrm{out}}}{B_{\mathrm{nf}}} \\
& Q=2 \int_{0}^{B / 2} q_{\mathrm{sf}}(x) \mathrm{d} x-B \bar{\sigma}_{\mathrm{z}}=\frac{\left(B_{\mathrm{nf}}-B\right) V_{\mathrm{in}}-B V_{\mathrm{out}}}{B_{\mathrm{nf}}} \\
& \mathbb{I} \\
& v_{\mathrm{dev}}=v_{\text {in }}-v_{\text {out }}
\end{aligned}
$$

while

$$
\bar{\sigma}_{\mathrm{z}}=\frac{2}{B_{\mathrm{nf}}}\left(\int_{0}^{B / 2} q_{\mathrm{sf}}(x) \mathrm{d} x+\int_{B / 2}^{B_{\mathrm{nf}} / 2} p_{\mathrm{sf}} \mathrm{d} x\right)
$$

is the average pressure along the upper $\Omega_{\mathrm{nf}}$ boundary. Both variable pairs in equations (4) and (6) are formed by displacements and per unit length forces, in accordance with the plane strain assumption. The concept of the near-field domain can be simply exploited to handle loads outside the foundation footprint as if they were standard direct loads.

As suggested by Fig. 2, the variable pairs in equation (6) establish an interesting analogy between a soil specimen in a triaxial apparatus and a vertically loaded strip footing. This analogy can be grasped by re-interpreting the concepts of 'isotropic' (Fig. 2(a)) and 'deviatoric' (Fig. 2(b)) loading in a global SFI sense, as follows.

(a) A soil specimen undergoes isotropic loading when equal axial and radial stresses $\left(\sigma_{\mathrm{a}}\right.$ and $\left.\sigma_{\mathrm{r}}\right)$ are enforced and the stress deviator $q=\sigma_{\mathrm{a}}-\sigma_{\mathrm{r}}$ is constantly nil. Similarly,
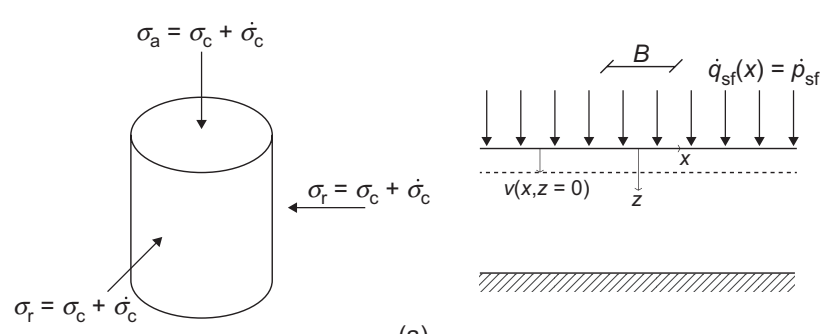

(a)
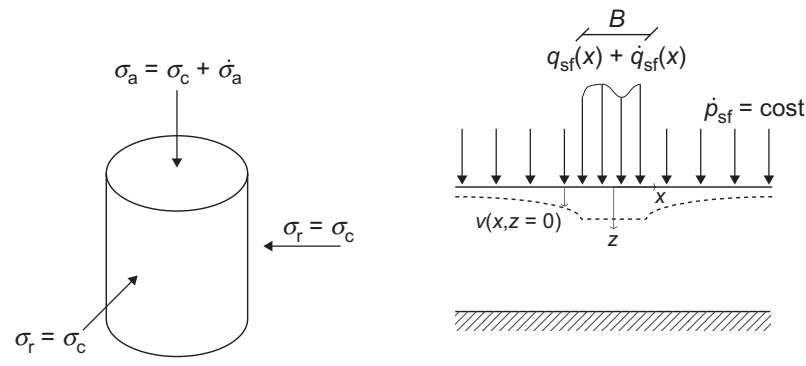

(b)

Fig. 2. Static analogy between triaxial tests and strip footing problems: comparison between (a) isotropic and (b) deviatoric loading

a uniform surface compression with $q_{\mathrm{sf}}=p_{\text {sf }}$ can be regarded as a sort of isotropic compression on the soil layer. This statement stems from the conceptual analogy between the $\left(\sigma_{\mathrm{a}} ; \sigma_{\mathrm{r}}\right)$ and $\left(V_{\mathrm{in}} ; V_{\text {out }}\right)$ pairs and justifies the adjectives 'isotropic' and 'deviatoric' for $P$ and $Q$ forces, respectively. It could be checked that, during generalised isotropic loading (generalised isotropic loading does not induce an isotropic stress state within the soil layer, but rather oedometric), $Q=0$ and $P$ is still given by a linear combination of the generalised axial and radial stresses, $V_{\text {in }}$ and $V_{\text {out }}$. As for kinematics, generalised isotropic compression produces a uniform settlement of the soil layer, so that $v_{\mathrm{vol}}=v_{\text {in }}=v_{\text {out }}$ and a nil generalised deviatoric strain $v_{\text {dev }}$ results.

(b) The triaxial compression of soil specimens features constant radial confinement (the cell pressure $\sigma_{\mathrm{c}}$ ) and increasing axial load, so that a constant ratio between deviatoric and isotropic stress increments is imposed up to shear failure $(\dot{q} / \dot{p}=3$, dots represent increment). Likewise, imposing a load increment on the foundation $\left(\dot{q}_{\text {sf }}>0\right)$ at constant lateral surcharge resembles a deviatoric loading stage, eventually inducing a sheartype collapse (see 'Bearing capacity and pre-failure response'). It can also be proven that the loading programme $\dot{V}_{\text {in }}>0$ and $\dot{V}_{\text {out }}=0$ yields a constant loading ratio $\dot{Q} / \dot{P}=\left(B_{\mathrm{nf}}-B\right) / B_{\mathrm{nf}}$, still in tight analogy with triaxial soil testing.

Negative $Q$ values denote uplifting loading conditions, in which the lateral surcharge is significantly larger than the direct load on the foundation. This further analogy is still meaningful, as uplifting loading can be regarded as a generalised triaxial extension. It should be finally noted that $\Gamma$ and $v_{\Omega}$ have no triaxial counterparts, since self-weight effects in small-sized specimens are normally neglected.

\section{Bearing capacity and pre-failure response}

The bearing capacity of a strip footing on a homogeneous soil layer is usually evaluated by using the well-known Terzaghi formula, related to a Prandtl-type shear failure mechanism (Chen, 2013) 


$$
\begin{aligned}
\left(2 \int_{0}^{B / 2} q_{\mathrm{sf}}(x) \mathrm{d} x\right)_{\mathrm{lim}} & =V_{\mathrm{in}, \lim } \\
& =B\left(p_{\mathrm{sf}} N_{\mathrm{q}}+c N_{\mathrm{c}}+\frac{1}{2} B \gamma N_{\gamma}\right)
\end{aligned}
$$

where $N_{\mathrm{q}}, N_{\mathrm{c}}$ and $N_{\gamma}$ are bearing capacity factors depending on the soil friction angle (Bowles, 1996) and $c$ is the soil cohesion. After substituting definitions (4) and (6), equation (8) can be rewritten as

$$
Q_{\text {lim }}=\tilde{N}_{\mathrm{q}} P+c B \tilde{N}_{\mathrm{c}}+\frac{1}{2} \Gamma \tilde{N}_{\gamma}
$$

where the following redefined capacity factors

$$
\begin{aligned}
& \tilde{N}_{\mathrm{q}}=\frac{\left(B / B_{\mathrm{nf}}\right)\left(N_{\mathrm{q}}-1\right)}{\left[B /\left(B_{\mathrm{nf}}-B\right)\right] N_{\mathrm{q}}+1} \\
& \tilde{N}_{\mathrm{c}}=\frac{1}{1+\left[B /\left(B_{\mathrm{nf}}-B\right)\right] N_{\mathrm{q}}} N_{\mathrm{c}} \\
& \tilde{N}_{\gamma}=\frac{B^{2}}{B_{\mathrm{nf}} H_{\mathrm{nf}}} \frac{1}{1+\left[B /\left(B_{\mathrm{nf}}-B\right)\right] N_{\mathrm{q}}} N_{\gamma}
\end{aligned}
$$

depend not only on the soil strength (through $N_{\mathrm{q}}, N_{\mathrm{c}}$ and $N_{\gamma}$ ) but also on the footing breadth and the $\Omega_{\mathrm{nf}}$ domain size. Equation (9) defines a planar failure locus in the $P Q \Gamma$ space, bounding all the admissible vertical loading combinations. From a mechanical standpoint, a sort of Mohr-Coulomb criterion for the whole foundation arises, in which the limit deviatoric load is still given by a pressure-dependent component $\left(\tilde{N}_{\mathrm{q}} P\right)$ and a generalised cohesive term - including here both cohesive $\left(c B \tilde{N}_{\mathrm{c}}\right)$ and gravitational $\left((1 / 2) \Gamma \tilde{N}_{\gamma}\right)$ resisting mechanisms.

The above derivations inspire the conception of a new ME framework for modelling the response of shallow foundations to both direct and configurational loading, from the onset to failure. The enlightening analogy between strip footings and triaxial soil specimens suggests that well-established concepts should be borrowed from strain-hardening plasticity and applied to the present SFI problem as well. Accordingly, this requires the formulation of appropriate ME equations in the $P Q \Gamma$ space, enabling the simulation of mixed direct/configurational loading programmes. In this context, variations in $\Gamma$ could be, for instance, produced by fluctuations in the phreatic level and should in principle enable the ME modelling of subsidence effects.

Provided suitable static/kinematic variables and the failure criterion, the formulation of an elastic-plastic configurationsensitive ME model will also require: $(a)$ an elastic (preyielding) relationship; $(b)$ a yield locus $f=0 ;(c)$ a plastic potential $g$; and $(d)$ hardening rule(s) governing the evolution of the elastic domain during plastic straining (until the current stress point approaches the failure line $F=0$ ). These well-known concepts are qualitatively illustrated in Fig. 3 for a footing on a cohesionless/weightless soil, that is, for the $\Gamma=0$ cross-section in the $P Q \Gamma$ space.

In Fig. 3, the slope $M$ of the failure $P Q$ locus is related to the $\tilde{N}_{\mathrm{q}}$ factor in equation (9), whereas the generalised cohesive term vanishes when the soil cohesion $c$ and unit weight $\gamma$ are nil (Fig. 3). Importantly, the concept of elastic domain is to be meant in a wider sense, as the footing response can never be fully elastic (plastifications under the footing corners will always occur since the very onset of loading). Nevertheless, the concept of yield locus can still be exploited to identify the inception of markedly plastic responses, while unloading/reloading processes will be regarded as nearly elastic/reversible (although plastic strains may still be

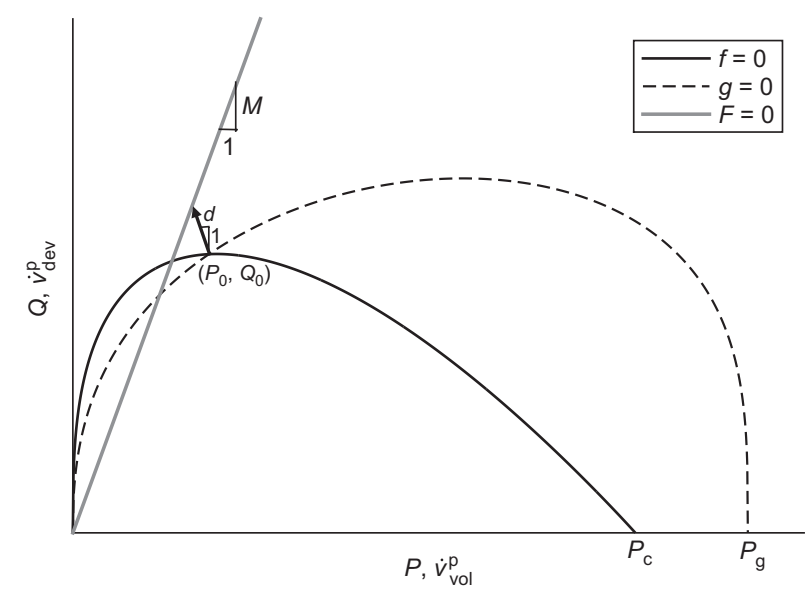

Fig. 3. Qualitative $P Q$ cross-sections of relevant ME loci

produced at certain soil points). The definition of a yield locus will also rule how loading, unloading and, possibly, neutral loading should be interpreted in the present $\mathrm{ME}$ framework.

Figure 3 also shows that even the concept of dilatancy can be properly generalised. Based on the volumetric and deviatoric attribute of the kinematic variables $v_{\mathrm{vol}}$ and $v_{\mathrm{dev}}$, a global dilatancy can be defined, with its plastic component $d$ being associated with the gradient of the plastic potential function

$$
\left\{\begin{array}{c}
\dot{v}_{\mathrm{vol}}^{\mathrm{pl}} \\
\dot{v}_{\mathrm{dev}}^{\mathrm{pl}}
\end{array}\right\}=\dot{\lambda}\left\{\begin{array}{l}
\partial g / \partial P \\
\partial g / \partial Q
\end{array}\right\} \Rightarrow d=\frac{\dot{v}_{\mathrm{vol}}^{\mathrm{pl}}}{\dot{v}_{\mathrm{dev}}^{\mathrm{pl}}}=\frac{\partial g / \partial P}{\partial g / \partial Q}
$$

\section{Identification of the near-field domain}

The determination of $\Omega_{\mathrm{nf}}$ is extremely problem-specific, as it is influenced by the loading combination and soil conditions (e.g. in-site layering, water table depth and soil properties). Here, $\Omega_{\mathrm{nf}}$ is identified for the situation depicted in Fig. 1 and relates to the formation of a Prandtl-type shear mechanism (Fig. 4) - as is the case of (ideal) soils obeying an associated plastic flow rule (Chen, 2013).

Based on the observations in the 'Introduction', it seems reasonable to set $B_{\mathrm{nf}}$ equal to the width of a typical Prandtl mechanism (Fig. 4). However, as limit analysis solutions do not hold for non-associated materials, it can be shown that the kinematics of the failure mechanism can be quite accurately captured through a redefined soil friction angle $\phi^{*}$ (Drescher \& Detournay, 1993):

$$
\tan \phi^{*}=\frac{\cos \psi \sin \phi}{1-\sin \psi \sin \phi}
$$

where $\psi$ denotes the soil dilatancy angle at failure (the same redefinition has been also exploited for other problems involving plane-strain shear banding (Davis, 1968; Vermeer, 1990; di Prisco \& Pisanò, 2011a)). Although the soil constitutive behaviour is not perfectly elastic-plastic, the following $B_{\mathrm{nf}}$ definition will be shown to perform well under all the previous assumptions

$$
B_{\mathrm{nf}}=B\left[1+2 \frac{\mathrm{e}^{(\pi / 2) \tan \phi^{*}}}{\tan \left(\pi / 4-\phi^{*} / 2\right)}\right]
$$

The suitability of equation (13) will be further supported in the following section. Conversely, no discussion about the 


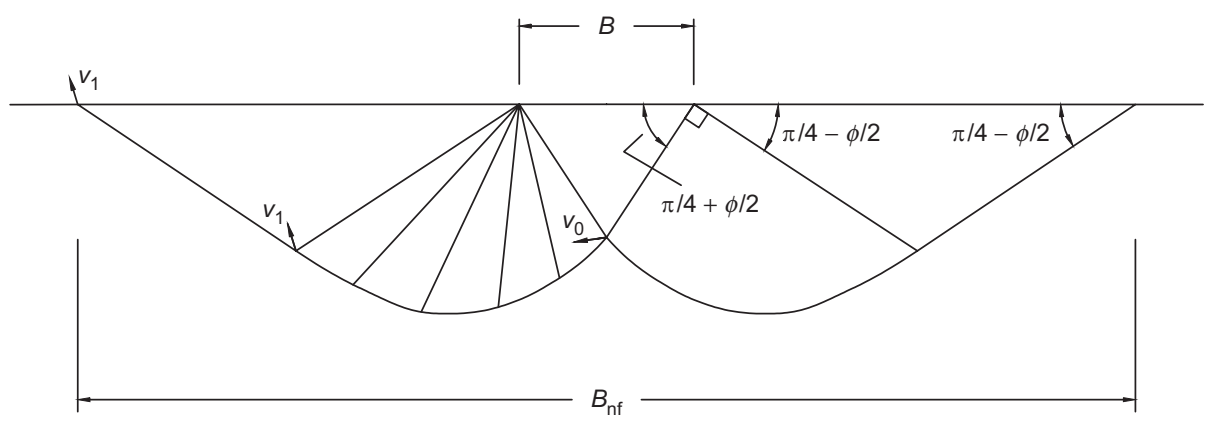

Fig. 4. Horizontal size of $\Omega_{\mathrm{nf}}$ for a Prandtl-type mechanism

vertical size of $\Omega_{\mathrm{nf}}, H_{\mathrm{nf}}$ will be reported, as it is irrelevant to the present case of weightless soil.

\section{MODEL FORMULATION AND CALIBRATION}

In this section the new configuration-sensitive ME model is formulated and calibrated against FE results. A numerical investigation of configurational effects has been preferred because (a) FE results provide detailed input to ME modelling, and $(b)$ no foundation on an ideal weightless soil could be tested in reality.

\section{Strip footing FE modelling}

The whole FE study has been carried out by using the commercial code TNO Diana (Manie, 2014). The soil domain has been discretised by using quadratic six-node triangular elements (Zienkiewicz \& Taylor, 2000), avoiding the locking effects often produced by low-order elements (Nagtegaal et al., 1974; Marti \& Cundall, 1982; Sloan \& Randolph, 1982).

Since the problem in Fig. 1 is symmetric with respect to the vertical axis $x=0$, only a half-domain has been numerically analysed under the following boundary conditions: $(a)$ no lateral displacement along vertical edges; $(b)$ fixed nodes along the horizontal bottom boundary; $(c)$ vertical surface pressure $p_{\text {sf }}$ for $x>B / 2 ;(d)$ prescribed vertical settlement with no horizontal displacement for $x \leq B / 2$ (this reproduces a rigid rough foundation).

Although most bearing capacity theories for soils have been developed in the framework of perfect elastic-plasticity (Chen, 2013), a strain-hardening constitutive relationship was preferred herein, namely the so-called modified MohrCoulomb (MMC) model (Groen, 1997). The MMC model available in TNO Diana (Manie, 2014) features

(a) pressure-dependent elastic bulk modulus

(b) non-linear strain hardening, with mobilised friction angle depending on the equivalent deviatoric plastic strain

(c) two distinct yielding mechanisms for shear and radial (e.g. oedometric) loading paths

(d) smooth deviatoric section of the failure locus in the $\pi$-plane, matching the Mohr-Columb limits under triaxial compression and extension

(e) non-associated plastic flow rule, allowing for both compactive and dilative volumetric behaviour according to the Rowe's law (Rowe, 1962).

Details about the MMC constitutive formulation and the calibration of soil parameters are provided in Appendix 1 . Calibration has been here performed against experimental data concerning Toyoura sand medium-dense specimens.
Footing 'triaxial response'. The footing response to vertical (direct) loading is here visualised by adopting the above static/kinematic variables, at three different levels of lateral surcharge $\left(p_{\mathrm{sf}}=25,50,100 \mathrm{kPa}\right)$. As an example, Fig. 5 illustrates the FE results for a $2 \mathrm{~m}$-wide footing resting on a medium-dense sand layer. The size of the (half) soil domain is $40 \times 17 \mathrm{~m}(H / B=8 \cdot 5)$, that is enough to prevent any boundary effect on the computed bearing capacity.

Figure 5 points out the similarities between the triaxial response of a medium-dense sand specimen and the settlement response of a strip footing, when the newly defined static/kinematic variables are employed.

(a) The deviatoric load-settlement curve $\left(Q-v_{\mathrm{dev}}\right)$ exhibits a hardening behaviour up to failure.

(b) This is the same as for triaxial compression tests, the $Q-P$ loading path has a constant inclination $\left(\dot{Q} / \dot{P}=\left(B_{\mathrm{nf}}-B\right) / B_{\mathrm{nf}}\right)$ and the limit load is pressure dependent, while the failure loading ratio depends on both the soil properties and the footing size.

(c) The final distribution of the surface settlement confirms that equation (13) is suitable to detect the transition from the plastic to the elastic zone as shear failure is attained. Such a transition can be associated with the inflection point in the settlement distribution, whose location is markedly affected by the soil non-associativeness (setting $\phi^{*}=\phi$-i.e. $\psi=\phi$ - in equation (13) would result in a much larger near-field domain size).

(d) The generalised volumetric response of the foundation resembles what is normally found for medium-dense to dense sand specimens; that is, an initial compaction followed by dilation. The three curves in Fig. 5(d) approach the same final inclination, providing the failure value of the generalised dilatancy defined in equation (11).

The inclination $M$ of the $P Q$ failure locus in Fig. 5(b) does not exactly coincide with $\tilde{N}_{\mathrm{q}}$ in equation $(10)$, because $(a)$ the MMC model is non-associated (De Borst \& Vermeer, 1984; Manoharan \& Dasgupta, 1995; Frydman \& Burd, 1997; Yin et al., 2001; Loukidis \& Salgado, 2009) and (b) the deviatoric $\pi$-section of the MMC failure locus circumscribes the Mohr-Coulomb locus considered in the Terzaghi formula (8). The interplay between these two factors produces plane-strain bearing capacities larger than standard predictions based on associative Mohr-Coulomb plasticity (deviations in the order of $13 \%$ ). Nonetheless, the expected occurrence of a Prandtl-type failure mechanism has still been observed.

It is also worth observing that 'oscillating' FE curves as in Fig. 5 have been widely documented by several previous studies (De Borst \& Vermeer, 1984; Manoharan 


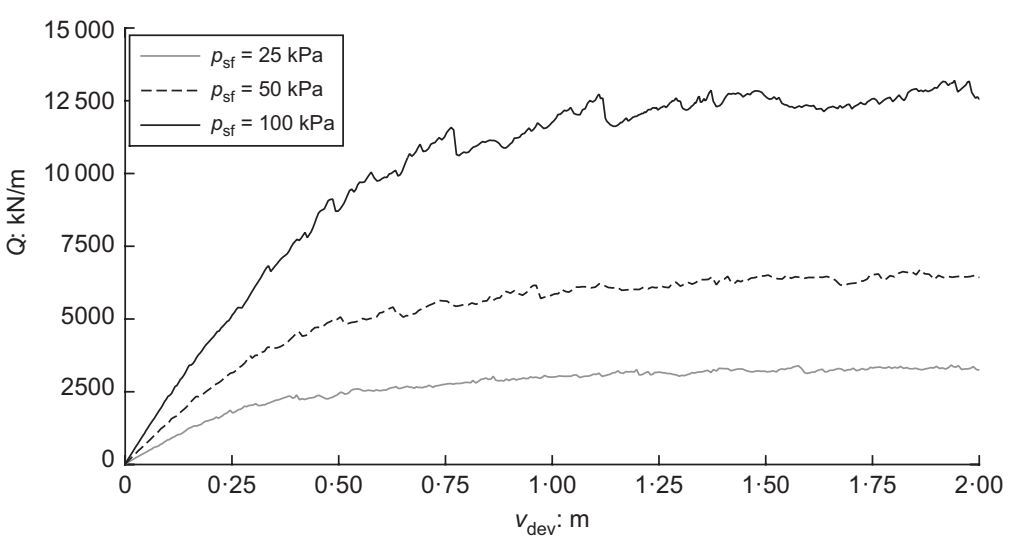

(a)

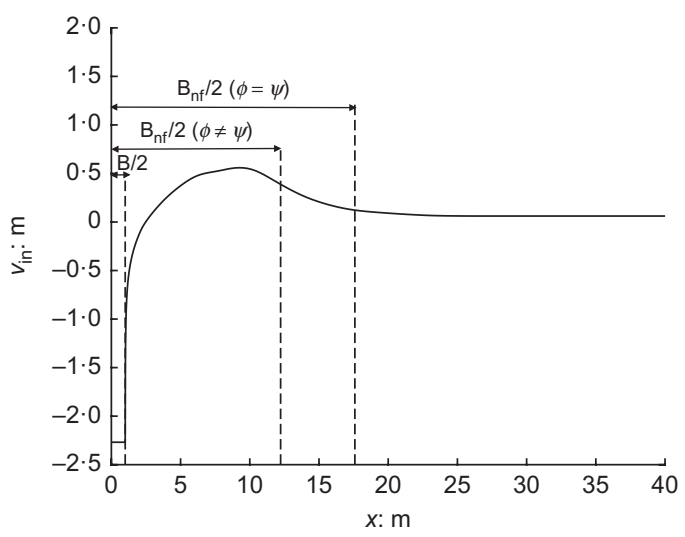

(c)

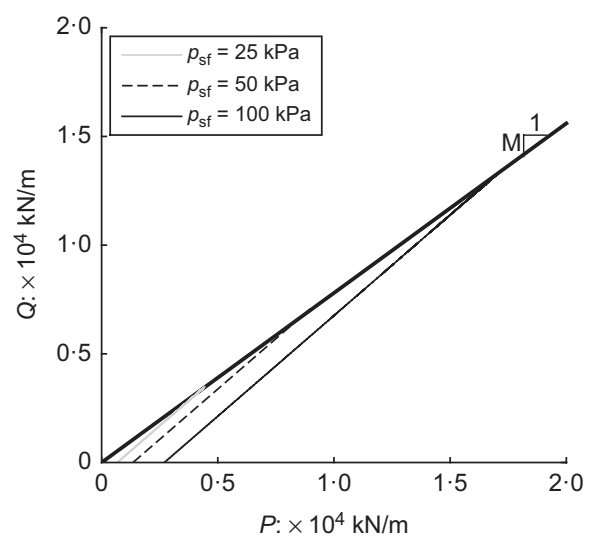

(b)

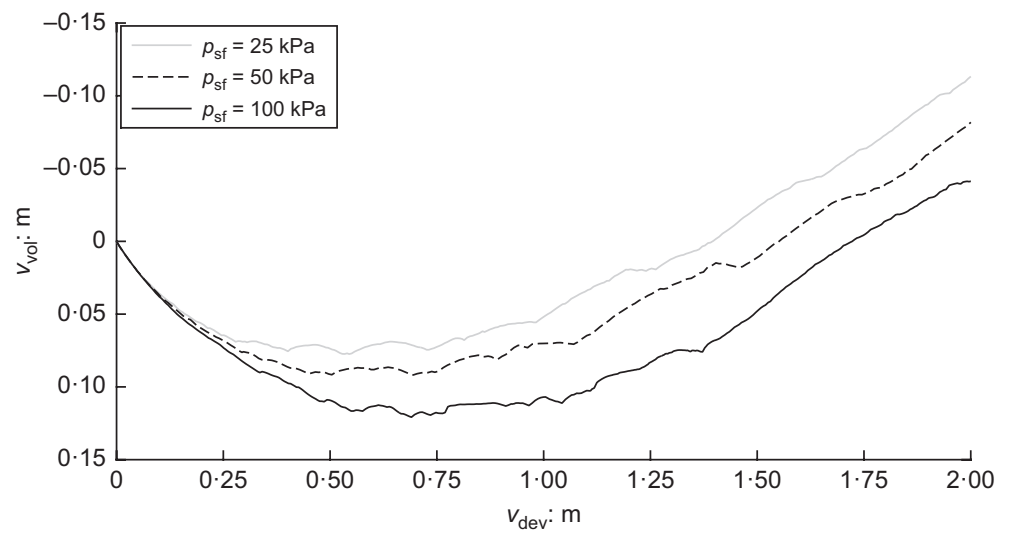

(d)

Fig. 5. Footing response at different $p_{\text {sf }}$ (a) deviatoric load-settlement curves; (b) $P Q$ loading paths; (c) final distribution of surface settlement $\left(p_{\mathrm{sf}}=50 \mathrm{kPa}\right) ;(\mathrm{d})$ generalised volumetric response

\& Dasgupta, 1995; Yin et al., 2001; Erickson \& Drescher, 2002; Loukidis \& Salgado, 2009) and attributed to the soil non-associativeness (Loukidis \& Salgado, 2009; di Prisco \& Pisanò, 2011a; di Prisco et al., 2012).

\section{Formulation of ME constitutive equations}

Based on the conceptual analogy between soil element testing and footing response, new configuration-sensitive ME equations have been straightforwardly formulated in the framework of 'displacement'-hardening plasticity (Muir Wood, 2004; Nova, 2013).

Elastic law. Since the MMC soil model features a nonlinear elastic behaviour (see Appendix 1), the ME elastic law has to be non-linear as well. In particular, the following incremental matrix form has been selected

$$
\left\{\begin{array}{l}
\dot{v}_{\mathrm{vol}}^{\mathrm{e}} \\
\dot{v}_{\mathrm{dev}}^{\mathrm{e}}
\end{array}\right\}=\left[\begin{array}{cc}
C_{\mathrm{PP}}^{\mathrm{e}} & 0 \\
0 & C_{\mathrm{QQ}}^{\mathrm{e}}
\end{array}\right]\left\{\begin{array}{l}
\dot{P} \\
\dot{Q}
\end{array}\right\}
$$

where the elastic compliances $C_{\mathrm{PP}}^{\mathrm{e}}$ and $C_{\mathrm{OQ}}^{\mathrm{e}}$ need to depend explicitly on the loading level and relevant geometrical factors $\left(B, H, B_{\mathrm{nf}}\right) . C_{\mathrm{PP}}^{\mathrm{e}}$ represents the oedometric elastic compressibility of the stratum, providing the settlement induced by a uniform surface compression $(\dot{Q}=0)$. The diagonal form of the elastic compliance matrix has been assumed as the most convenient, energetically proper option: in fact, while the bottom left entry $C_{\mathrm{QP}}^{\mathrm{e}}$ needs to be nil by definition, that would not be the case for the top right term $C_{\mathrm{PQ}}^{\mathrm{e}}$. This aspect is a direct consequence of the specific static/kinematic variables employed, although the simplified elastic law (14) will still prove accurate in the following.

Yield and failure loci. The yield locus $f=0$ has been formulated as

$$
f=Q^{2}-Q_{0}^{2}\left|1-\frac{P}{P_{\mathrm{c}}}\right|^{2 \beta}\left|\frac{P}{P_{\mathrm{c}}}\right|^{2 \gamma} \operatorname{sgn}\left[\left(1-\frac{P}{P_{\mathrm{c}}}\right)\left(\frac{P}{P_{\mathrm{c}}}\right)\right]=0
$$

where the 'absolute value' and 'sign' functions have been introduced to ensure $f$ is real and negative inside the elastic domain, real and positive outside (Dattola, 2011; Pisanò et al., 2014). $P_{\mathrm{c}}$ is a hardening variable governing the locus size, whereas exponents $\beta$ and $\gamma$ are shape parameters to be calibrated under the restrictions $0<\beta<1$ and $0<\gamma<1$ (convexity would be lost out of the $0-1$ range). To guarantee a homothetic expansion of the yield locus, $Q_{0}$ needs to be proportional to $P_{\mathrm{c}}$

$$
Q_{0}=m \frac{\gamma}{\beta+\gamma}\left(\frac{\beta+\gamma}{\beta}\right)^{\beta}\left(\frac{\beta+\gamma}{\gamma}\right)^{\gamma} P_{\mathrm{c}}
$$

where $m$ is an additional ME parameter setting the obliquity $Q / P$ at the vertex of the yield locus (Fig. 6).

According to standard concepts in strain-hardening plasticity, the expansion of the yield locus ends when the current stress point attains the failure locus $F=0$. In this case, the failure locus encompasses all the $Q-P$ couples associated with a Prandtl-like footing collapse. Such a locus directly stems from equation (9) for shallow foundations on weightless/cohesionless soils

$$
F=Q-M P=0
$$




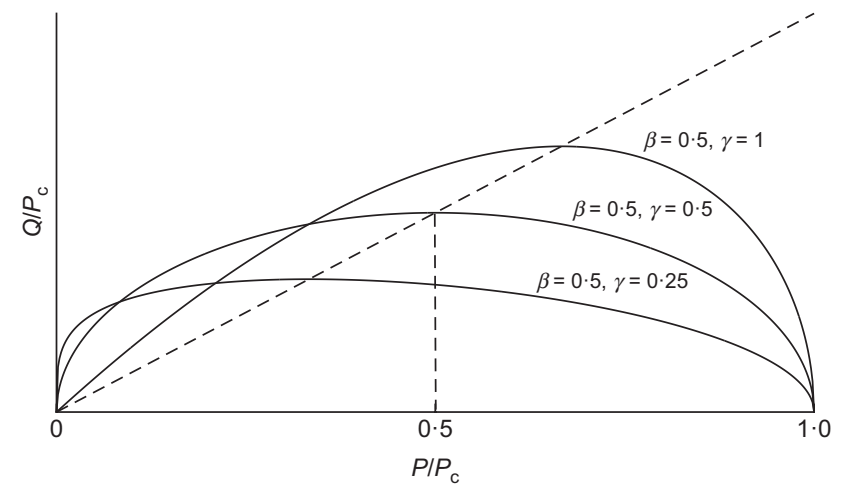

Fig. 6. Influence of parameters $\beta\left(\beta_{\mathrm{g}}\right)$ and $\gamma\left(\gamma_{\mathrm{g}}\right)$ on the shape of the ME yield locus (plastic potential)

where $M$ does not exactly coincide with $\tilde{N}_{\mathrm{q}}$ (see the previous discussion on this point).

Hardening rule. In accordance with what is shown in Fig. 5(d), the hardening rule for $P_{\mathrm{c}}$ has been selected by assuming that both volumetric and deviatoric plastic displacements contribute to hardening (Nova, 1977)

$$
\dot{P}_{\mathrm{c}}=\frac{P_{\mathrm{c}}}{H C_{\mathrm{p}}}\left(\dot{v}_{\mathrm{vol}}^{\mathrm{p}}+D \dot{v}_{\mathrm{dev}}^{\mathrm{p}}\right)
$$

in which $C_{\mathrm{p}}$ governs the plastic compliance of the sand layer under isotropic compression, while $D$ sets the generalised dilatancy at failure $\left(d=-\mathrm{D}\right.$ when $\left.\dot{P}_{\mathrm{c}}=0\right)$. For Prandtl-type failure, $D$ is not affected by the footing breadth $B$, but it does depend on the kind of soil considered. The presence of the stratum thickness $H$ in equation (18) is motivated in Appendix 2.

It could also be observed that, according to the hardening rule equation (18), the elastic domain would shrink $\left(\dot{P}_{\mathrm{c}}<0\right)$ when dilatancy is higher than $D(d<-\mathrm{D})$. This may only occur for significantly low $P / P_{\mathrm{c}}$ ratios (high 'overconsolidation ratio'), that is, when the plastic potential is locally very steep in the $Q-P$ plane (Fig. 3). Strictly speaking, this conceptual finding would also imply a more complex failure locus definition, where the term 'failure' is associated with the locus of all maximum $Q$ values ever attainable: such a locus would in fact be formed by two distinct portions, namely, $(a)$ a curved branch from the yield surface at very low $P / P_{\mathrm{c}}$ ratios (corresponding with $d<-\mathrm{D}$ and softening response), followed by (b) the above straight line $F=0$.

Plastic potential. The analytical expression for the plastic potential is similar to equation (15)

$$
g=Q^{2}-Q_{0 \mathrm{~g}}^{2}\left(1-\frac{P}{P_{\mathrm{g}}}\right)^{2 \beta_{\mathrm{g}}}\left(\frac{P}{P_{\mathrm{g}}}\right)^{2 \gamma_{\mathrm{g}}}
$$

where $\beta_{\mathrm{g}}$ and $\gamma_{\mathrm{g}}$ are additional ME parameters, while $P_{\mathrm{g}}$ is a dummy variable to be evaluated by imposing the equality $g$ $\left(P_{0}, Q_{0}, P_{\mathrm{g}}\right)=0$ at the current (generalised) stress point $\left(P_{0}\right.$, $\left.Q_{0}\right)$ (Fig. 6). Since the plastic potential has a vertical tangent at $Q=0$ (Fig. 6), no deviatoric plastic displacement is produced during isotropic compression.

In the same way as for $Q_{0}$ in equation (15), $Q_{0 \mathrm{~g}} \propto P_{\mathrm{g}}$ guarantees a homothetic expansion of the plastic potential

$$
\begin{aligned}
& Q_{0 \mathrm{~g}}=\alpha_{\mathrm{g}} P_{\mathrm{g}} \Rightarrow \alpha_{\mathrm{g}}=\frac{\rho_{\mathrm{f}}^{1-\gamma_{\mathrm{g}}}}{\left(1-\rho_{\mathrm{f}}\right)^{\beta_{\mathrm{g}}}} M, \\
& \text { where } \rho_{\mathrm{f}}=\frac{1}{\beta_{\mathrm{g}} /\left(\gamma_{\mathrm{g}}-D / M\right)+1}
\end{aligned}
$$

The coefficient $\alpha_{\mathrm{g}}$ can be a priori set as in equation (20) to obtain a generalised dilatancy equal to $d=-\mathrm{D}$ at collapse; that is, when the loading ratio $Q / P$ attains the limit value $M$. As a consequence, only $\beta_{\mathrm{g}}$ and $\gamma_{\mathrm{g}}$ are free parameters, mostly depending on the soil type and the $B / H$ ratio between the footing width and the soil layer thickness (the latter dependence is further discussed in the following).

\section{Calibration of ME parameters}

The main details about the calibration of ME parameters are hereafter reported.

Elastic parameters. The elastic compliances $C_{\mathrm{PP}}^{\mathrm{e}} C_{\mathrm{QQ}}^{\mathrm{e}}$ in equation (14) are consistent with the non-linear elastic law embedded into the MMC model (see also Appendices 1 and 2).

Volumetric compliance $C_{\mathrm{PP}}^{\mathrm{e}}$. The compliance $C_{\mathrm{PP}}^{\mathrm{e}}$ governs the elastic settlement of the soil layer under uniform compression. In the case of weightless soil, $C_{\mathrm{PP}}^{\mathrm{e}}$ can be analytically determined (Appendix 2)

$$
C_{\mathrm{PP}}^{\mathrm{e}}=\frac{1}{E_{\mathrm{d}, \mathrm{ref}}} \frac{H}{\left(B_{\mathrm{nf}}\right)^{n}}\left(\frac{1+2 k_{0}^{\mathrm{e}}}{3 p_{\mathrm{ref}}} P\right)^{n-1}
$$

where $k_{0}^{\mathrm{e}}$ denotes the incremental elastic at-rest earth pressure coefficient, and $E_{\mathrm{d} \text {,ref }}$ and $p_{\text {ref }}$ are two elastic soil parameters (defined in Appendix 1).

Deviatoric compliance $C_{\mathrm{QQ}}^{\mathrm{e}}$. The deviatoric compliance $C_{\mathrm{QQ}}^{\mathrm{e}}$ is not trivial to determine, as it relates to non-uniform stress states within the soil layer and, based on the assumed MMC-elasticity, has to depend on both $P$ and $Q$ all along the loading path. In this respect, the following simplifying assumptions have been introduced

(a) $C_{\mathrm{QQ}}^{\mathrm{e}}$ only depends on the initial surface pressure $p_{\mathrm{sf}}=q_{\mathrm{sf}}$, the footing breadth $B$ and the aspect ratio $H / B$ of the soil layer

(b) $C_{\mathrm{QQ}}^{\mathrm{e}}$ does not vary significantly during loading, so that its initial tangent value can be maintained for the whole SFI analysis.

In the lack of analytical solutions, $C_{\mathrm{QQ}}^{\mathrm{e}}$ has been numerically determined by simulating the initial load-settlement curve for a footing resting on a non-linearly elastic soil. Preliminarily, the investigation of the elastic ME compliance has been kept somewhat on the side, postponing this effort to when a realistic non-weightless soil is considered.

Strength and dilatancy. The $M$ parameter in equation (17) would be equal to $\tilde{N}_{\mathrm{q}}$ in equation (9) for an associative perfectly elastic-plastic Mohr-Coulomb soil. The nonassociative MMC model does not fulfil this requirement, so that $M$ has been numerically derived. The three FE tests in Fig. 5 have been used to infer the failure loading ratio $Q / P$ at different $p_{\text {sf }}$ (Fig. 5(b)).

The dilatancy coefficient $D$ in equation (18) has been readily derived as the final steady slope of $v_{\mathrm{dev}}-v_{\mathrm{vol}}$ curves (Fig. 5(d)). $D$ could be quite accurately estimated by analysing the kinematics of the Prandtl failure mechanism, equation (4), as long as the role of non-associativeness is properly accounted for.

Yielding parameters. The shape of the yield locus, equation (27), has been identified according to its definition. As depicted in Fig. 7, a small set of FE tests has been performed in which

(a) the soil layer is first subjected to a given uniform compression (three different $p_{\text {sf }}$ considered) 


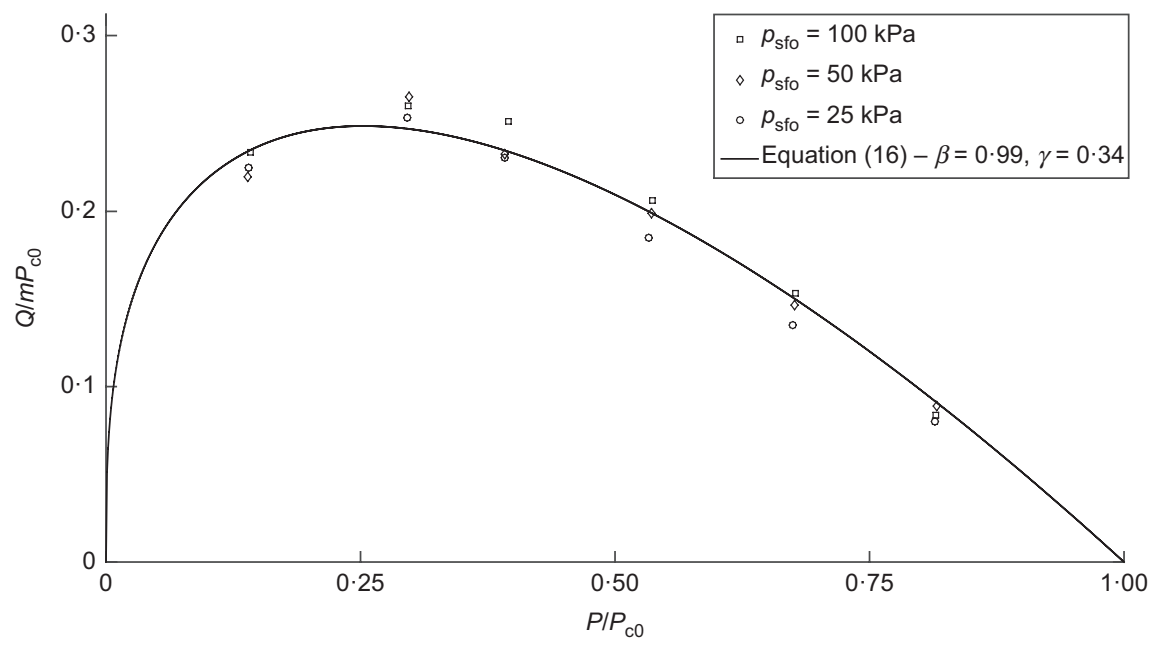

Fig. 7. Calibration of ME yielding parameters

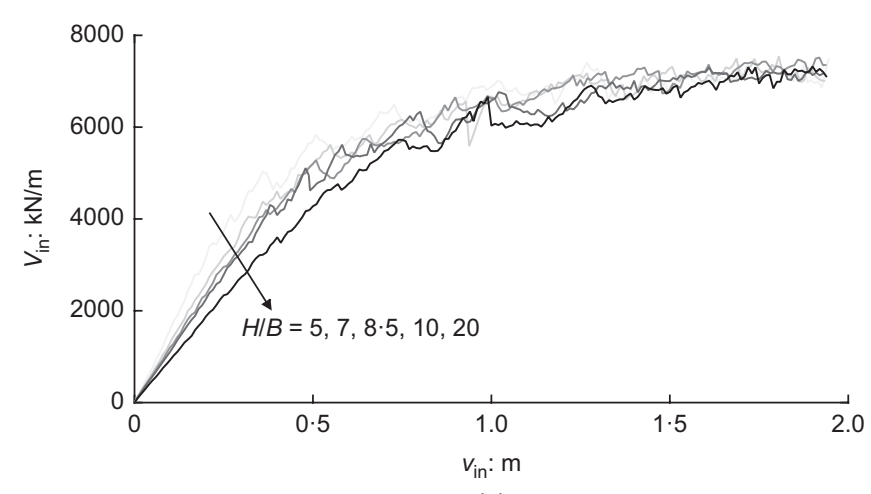

(a)

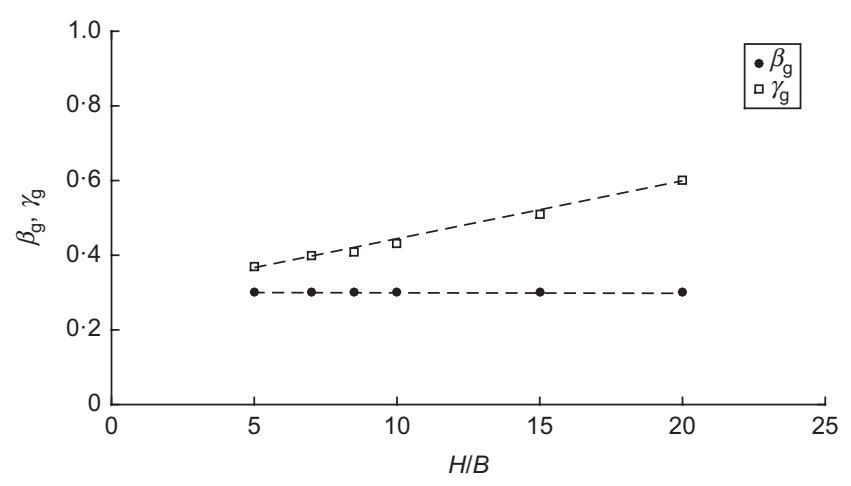

(b)

Fig. 8. Dependence of the footing response $(B=2 \mathrm{~m})$ on the $H I B$ ratio: (a) load-settlement curves; (b) exponents in the ME plastic potential function

(b) the soil surface is then unloaded up to a desired 'overconsolidation ratio' $\left(P / P_{\mathrm{c}}\right)$

(c) the foundation is vertically reloaded twice, for both cases of MMC elastic-plastic and non-linear elastic soil (MMC elastic law adopted). The reloading load-displacement curves are nearly coincident while no substantial plasticity is mobilised in the soil domain. Then, the following divergence between the elastic and elastic-plastic $Q-v_{\mathrm{dev}}$ curves can be inspected to identify suitable yielding points in the $P Q$ plane.

Figure 7 shows that the shape of the failure locus is practically the same for each confinement considered, so that a single $(\beta ; \gamma)$ pair has been calibrated. The parameter $m$ has been selected to best-fit the FE-predicted yield locus in the $Q-P$ plane, as well as to avoid any locking branch in the load-settlement $V_{\text {in }}-v_{\text {in }}$ footing response.

Hardening parameter. The $C_{\mathrm{p}}$ parameter in equation (18) governs the plastic compliance of the soil layer under generalised isotropic compression (i.e. oedometric loading), that is such that $\dot{v}_{\mathrm{dev}}^{\mathrm{p}}=0$. For this simple loading condition, the MMC equations can be analytically integrated over the soil domain and $C_{\mathrm{p}}$ estimated as follows

$$
C_{\mathrm{p}}=\frac{\delta}{1+e_{0}}
$$

where $\delta$ is a MMC soil parameter (Appendix 1) and $e_{0}$ is the initial void ratio of the soil layer. Details about the analytical derivation of equation (22) are given in Appendix 2.

Plastic potential parameters. The shape of the plastic potential function (Fig. 6) contributes to the (evolving) foundational stiffness. Accordingly, the parameters $\beta_{\mathrm{g}}$ and $\gamma_{\mathrm{g}}$ in equation (19) can be calibrated to obtain the best FE-ME match for a vertically loaded footing at constant lateral surcharge $\left(\dot{q}_{\text {sf }}>0, \dot{p}_{\text {sf }}=0\right)$.

Considering only one foundation width will be enough for calibration purposes, but it should be noted that the plastic potential parameters still depend on the $H / B$ ratio of the soil layer. In this respect, the FE results in Fig. 8(a) show how the $V_{\text {in }}-v_{\text {in }}$ load-settlement response is affected in stiffness (not in bearing capacity) by the $H / B$ ratio, with a higher vertical compliance at increasing layer thickness. Thus, in addition to the $H$-dependence in the hardening rule, equation (18), $H / B$-dependent $\beta_{\mathrm{g}}$ and $\gamma_{\mathrm{g}}$ values are anticipated. Fig. 8(b) shows the $\left(\beta_{\mathrm{g}} ; \gamma_{\mathrm{g}}\right)$ couples identified for a $2 \mathrm{~m}$-wide footing and $p_{\text {sf }}=50 \mathrm{kPa}$, that is, trying to obtain the best FE-ME match. Satisfactory ME simulations have been indeed obtained by keeping $\beta_{\mathrm{g}}$ constant and setting $\gamma_{\mathrm{g}}$ as a nearly linear function of $H / B$. The meaningfulness of this finding will be further commented on shortly.

The difference in ME plastic potential produced by thin and thick soil layers resembles the well-known distinction between dense and loose sands: in the same way as for loose soil samples, thicker soil layers underneath the foundation will result in increasing volumetric deformation, which is the 


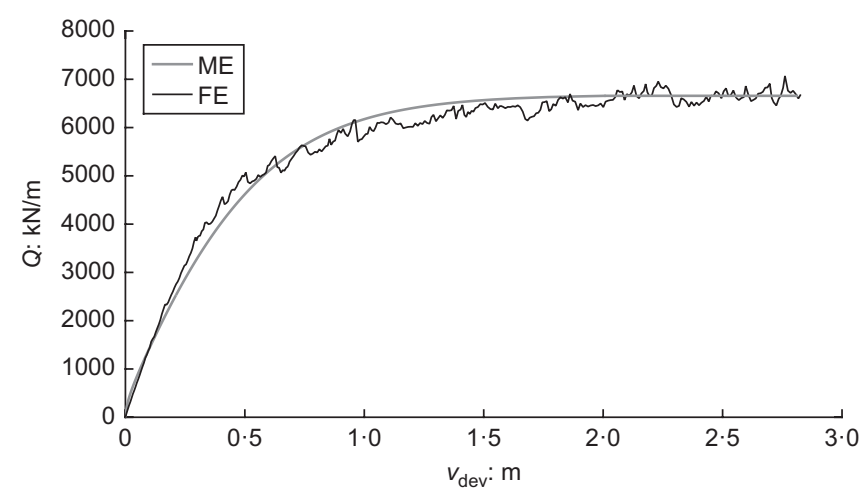

(a)

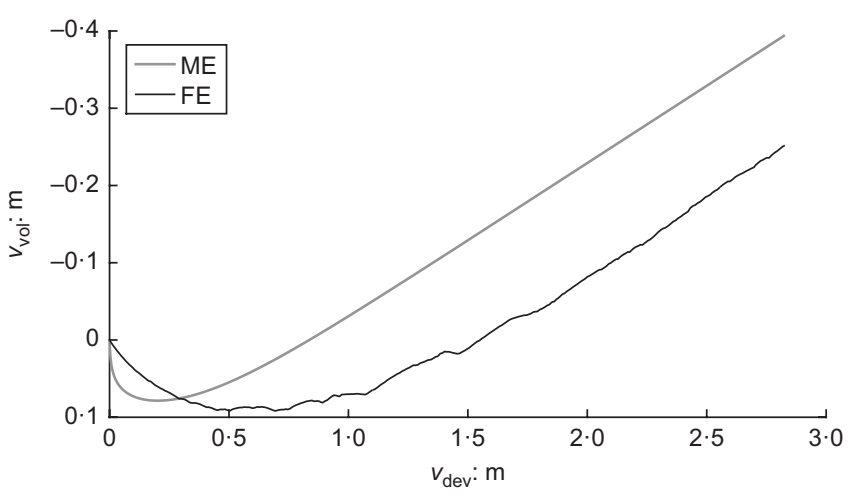

(b)

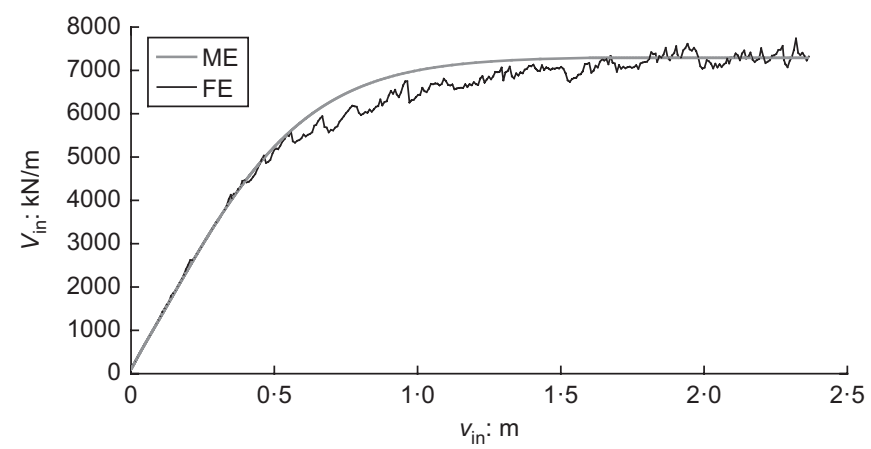

(c)

Fig. 9. FE-ME comparison for a vertically loaded 2 m-wide footing at $p_{\mathrm{sf}}=50 \mathrm{kPa}$ and $H I B=8 \cdot 5$ : (a) $Q-v_{\mathrm{dev}}$ response; (b) volumetric $v_{\mathrm{vol}}-v_{\mathrm{dev}}$ behaviour; (c) load-settlement $V_{\text {in }}-v_{\text {in }}$ curve

ME outcome of a $\gamma_{\mathrm{g}}$ increasingly larger than $\beta_{\mathrm{g}}$ (see Fig. 6). The dependence of $\beta_{\mathrm{g}}$ and $\gamma_{\mathrm{g}}$ on the $H / B$ ratio will deserve further investigation for the case including soil gravity.

The calibration phase for $B=2 \mathrm{~m}, \quad p_{\text {sf }}=50 \mathrm{kPa}$ and $H / B=5,7,8 \cdot 5,10,15,20$ produced results like those shown in Figs 9(a) and 9(b) in terms of $Q-v_{\text {dev }}$ and $v_{\mathrm{vol}}-v_{\mathrm{dev}}$ responses $(H / B=8 \cdot 5)$. The model accurately captures the deviatoric load-displacement response, while the generalised volumetric curve is well reproduced in terms of general trend and final dilatancy. It is practically relevant to show that, after trivial analytical manipulations, the loadsettlement response can be re-plotted in terms of standard variables $V_{\text {in }}-v_{\text {in }}$ (see 'Introduction'). Fig. 9(c) presents a still satisfactory $\mathrm{FE}-\mathrm{ME}$ agreement in the $V_{\text {in }}-v_{\text {in }}$ plane. The ME plastic parameters are all collected in Table 1, except the $H / B$-dependent $\gamma_{\mathrm{g}}$ (check Fig. 8(b)). The elastic compliances $C_{\mathrm{PP}}^{\mathrm{e}}$ and $C_{\mathrm{OQ}}^{\mathrm{e}}$ have been purposely excluded from the list as they are size-dependent (and the $C_{\mathrm{QQ}}^{\mathrm{e}}$ size-dependence has not yet been systematically investigated).

A further FE-ME comparison is plotted in Fig. 10 for the same $2 \mathrm{~m}$-wide foundation and two different lateral surcharges, $p_{\text {sf }}$ equal to $25 \mathrm{kPa}$ (Fig. 10(a)) and $100 \mathrm{kPa}$ (Fig. 10(b)). These results can be referred to as 'semi-blind' predictions because they have been only partially used for calibration, namely to explore the yield locus shape (Fig. 7). All the other plastic parameters calibrated for the $p_{\text {sf }}=50 \mathrm{kPa}$ case are still suitable for different lateral surcharges.

\section{MODEL VALIDATION}

This section is devoted to test the predictive capability of the above ME model. For this purpose, additional FE results have been produced for different foundation sizes, $H / B$ ratios and loading paths, while the same ME parameters in Table 1 have still been used. The following results aim to show that
Table 1. ME plastic parameters

\begin{tabular}{l|c|c|c|c|c|c|c}
\hline$M$ & $m$ & $\beta$ & $\gamma$ & $C_{\mathrm{p}}$ & $D$ & $\beta_{\mathrm{g}}$ & $\gamma_{\mathrm{g}}$ \\
\hline 0.78 & 0.6 & 0.99 & 0.34 & 0.0013 & 0.2 & 0.3 & Fig. 8(b) \\
\hline
\end{tabular}

the ME model calibrated against a few data (numerical here, but could also be experimental) can be actually applied to numerous SFI problems.

For the sake of brevity, the ME predictive performance is only illustrated in terms of load-settlement $V_{\text {in }}-v_{\text {in }}$ response, that is the main information needed in practice.

\section{Size-adaptivity}

The term size-adaptivity is here used to denote the ability of the ME model - calibrated for a specific foundation breadth $B$ - to predict the response of arbitrarily sized footings on a given soil and possibly varying $H / B$ ratio. This feature is extremely relevant to design, as it can be exploited to decide which foundation size results in some desired performance.

Figure 11 illustrates the ME predictions obtained for two different footing widths, $H / B=8.5$ and lateral surcharge $p_{\text {sf }}=50 \mathrm{kPa}$. The comparison between ME and FE curves in Fig. 11 is completely satisfactory, that is the ME model can be termed size-adaptive.

Figure 12 further confirms the suitable size-adaptivity of the ME model for two $10 \mathrm{~m}$-wide footings resting on two sand layers with $H / B$ equal to 8.5 (left) and 20 (right). It is worth remarking that not accounting for the $H / B$ dependence of $\gamma_{\mathrm{g}}$ (Fig. 8(b)) results in very poor prediction of the foundational compliance: $\gamma_{\mathrm{g}}=0.41$ is the value used for $H / B=8 \cdot 5$, apparently not appropriate for $H / B=20$. Fig. 12 also leads to the belief that the $\gamma_{\mathrm{g}}-H / B$ relationship is unique for any foundation breadth. 


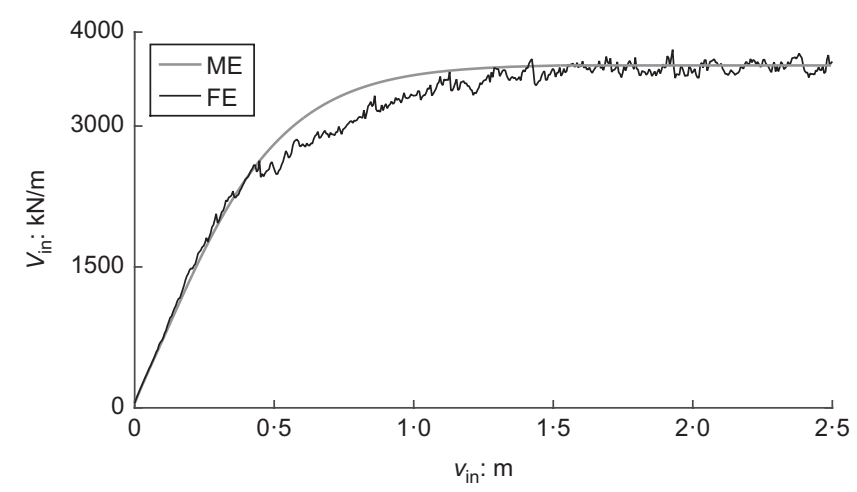

(a)

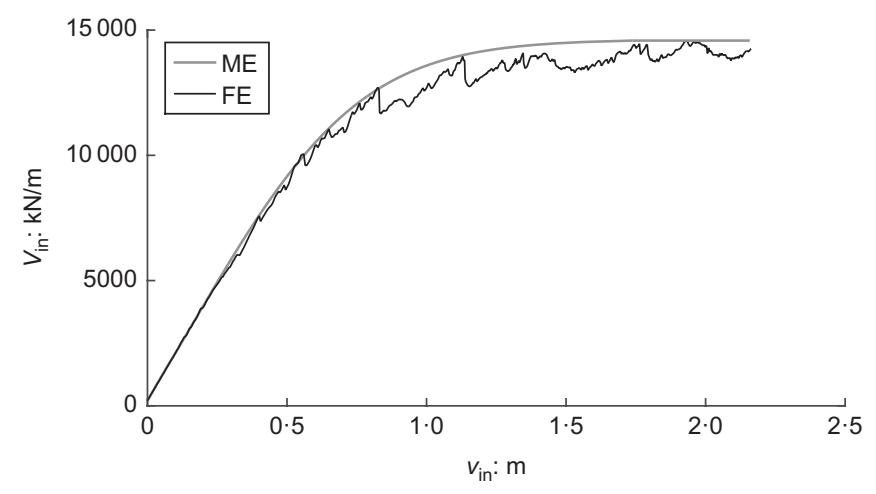

(b)

Fig. 10. ME semi-prediction of the FE load-settlement response for a vertically loaded $2 \mathrm{~m}$-wide footing at $(\mathrm{a}) p_{\mathrm{sf}}=25 \mathrm{kPa}$ and $(\mathrm{b}) p_{\mathrm{sf}}=100 \mathrm{kPa}$
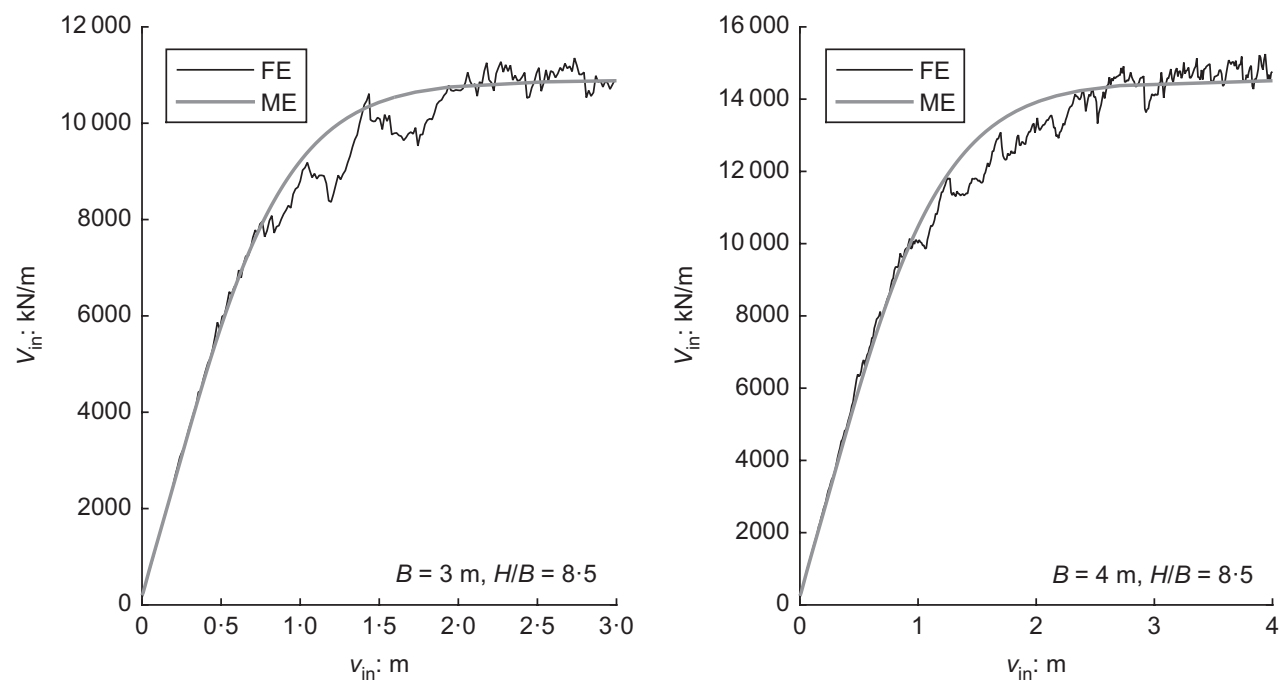

Fig. 11. ME-FE comparison at different footing widths and $H I B=8 \cdot 5\left(p_{\mathrm{sf}}=50 \mathrm{kPa}\right)-B=3 \mathrm{~m}(\mathrm{left}), B=4 \mathrm{~m}(\mathrm{right})$
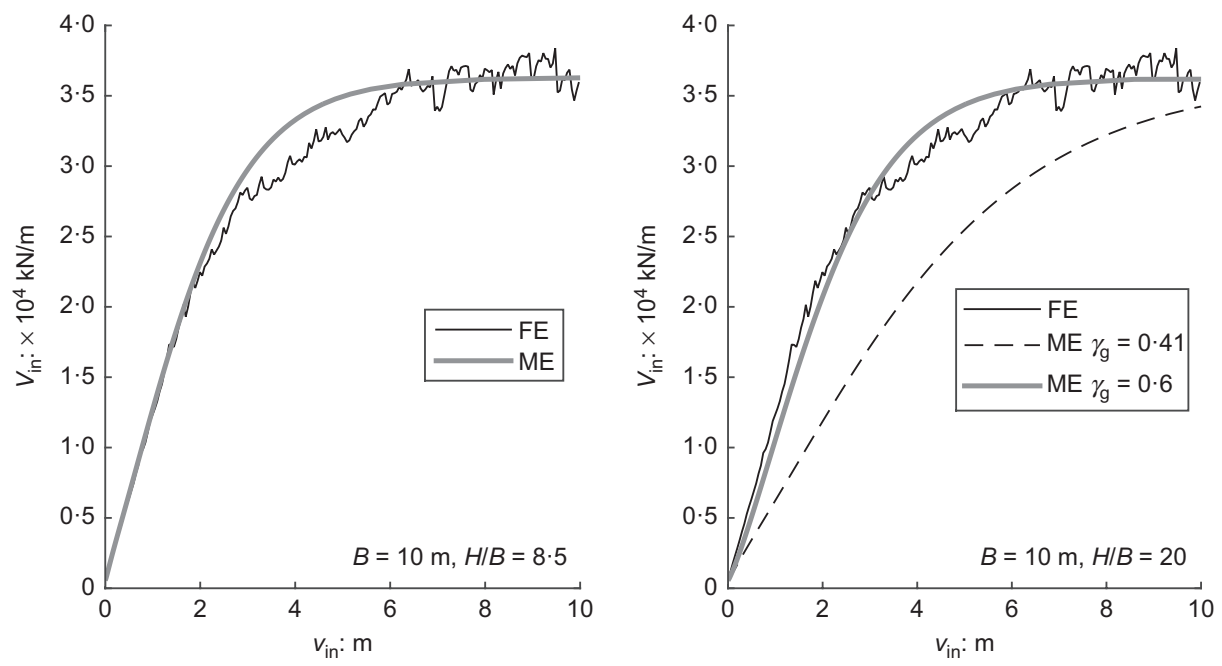

Fig. 12. ME-FE comparison at varying $H I B$ ratio and $H=10 \mathrm{~m}\left(p_{\mathrm{sf}}=50 \mathrm{kPa}\right)-H I B=8 \cdot 5($ left $), H I B=20$ (right)

Response to different loading paths

Not only geometrical factors, but also different loading conditions need to be investigated, as this relates to the chance of actually using the ME model in lieu of FE computations. In this subsection further ME-FE results are presented, relating to more complex loading conditions, not considered for calibration purposes. All the results given below refer again to the previous case with $B=2 \mathrm{~m}$ and $H / B=8 \cdot 5$.

Vertical loading paths. Obtaining inspiration from traditional soil testing, compressive vertical loading paths in the $Q P$ plane have been considered. As is shown in 


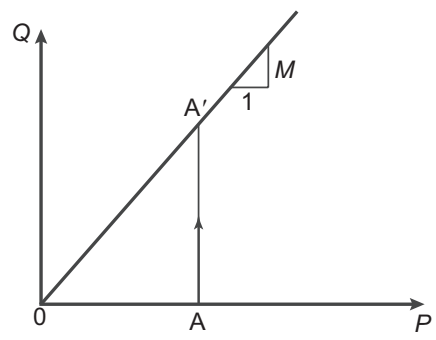

(a)

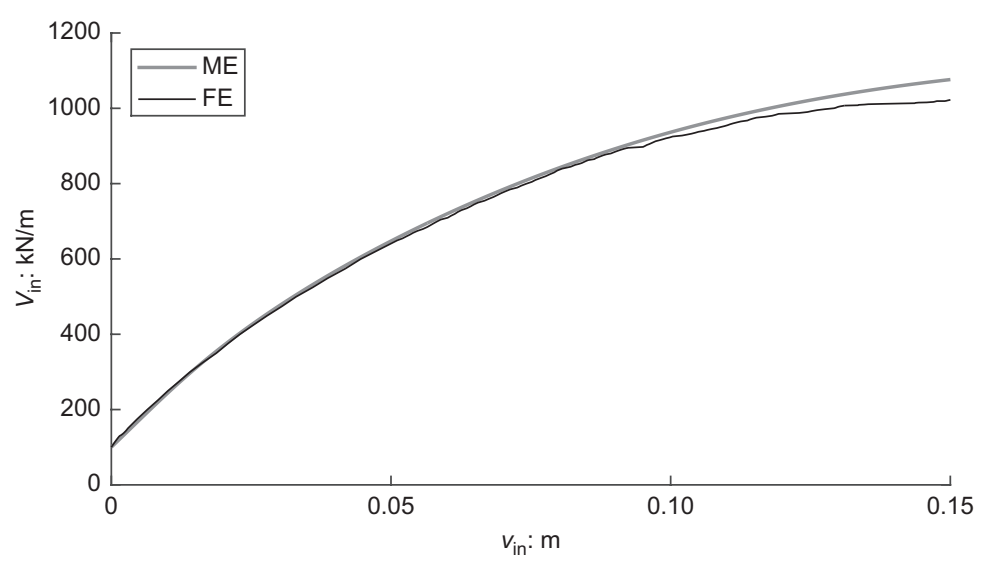

(b)

Fig. 13. Response to vertical $Q P$ loading: (a) $Q P$ loading path; (b) ME-FE comparison

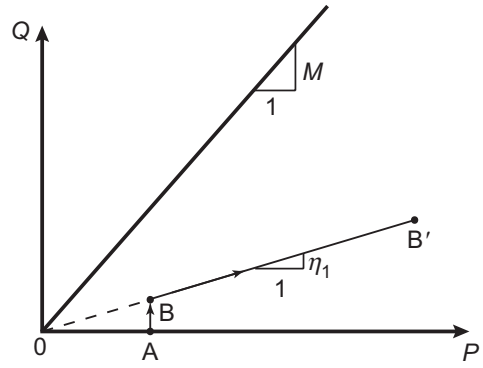

(a)

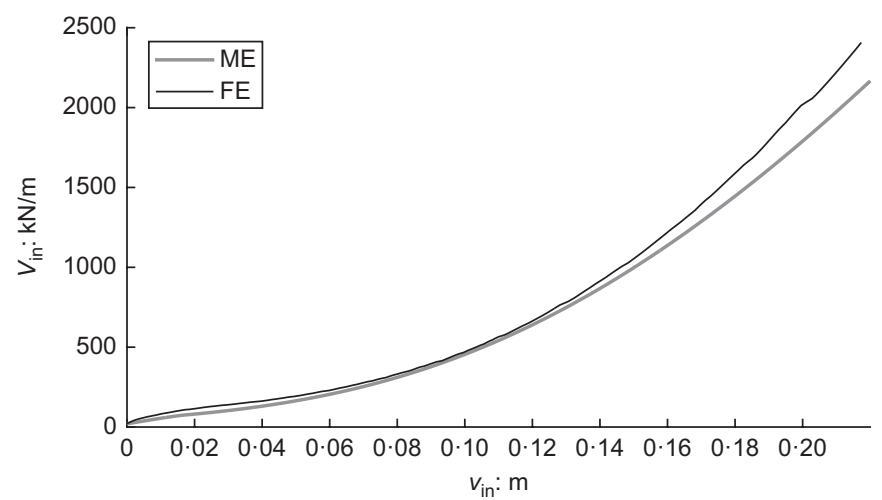

(b)

Fig. 14. Response to radial $Q P$ loading: (a) qualitative $Q P$ loading path; (b) ME-FE comparison for $\dot{Q} / \dot{P}=\eta_{1}=0 \cdot 2$

Fig. 13(a), vertical $Q P$ loading is enforced after an initial 'isotropic compression'; according to equation (6), a loading path characterised by $\dot{P}=0$ can be obtained by imposing $\dot{V}_{\text {in }}=-\dot{V}_{\text {out }} \Rightarrow \dot{q}_{\text {sf }} / \dot{p}_{\text {sf }}=-\left(B_{\text {nf }}-B\right) / B$, that is, loading the footing while proportionally unloading the lateral soil surface. Although this loading path is not common in practice, it still leads the system to a Prandtl-type failure in the presence of configurational loading - this is suggested by Fig. 13(a) and confirmed by the FE results. Fig. 13(b) reveals an excellent ME performance for a vertical $P Q$ path initiated from $Q=0\left(q_{\mathrm{sf}}=p_{\mathrm{sf}}=50 \mathrm{kPa}\right)$.

Radial loading paths. Unlike in standard soil testing, radial loading paths do not look particularly important in the present SFI context, but have been used to test the ME performance along loading paths not strictly producing shear failure under the footing.

Starting from a small uniform pressure $q_{\mathrm{sf}}=p_{\mathrm{sf}}=10 \mathrm{kPa}$ (point A in Fig. 14(a)), vertical $Q P$ loading has been applied up to a loading ratio $Q / P=\eta_{1}=0 \cdot 2$ (point $\mathrm{B}$ ); then, $\eta$-constant loading has been applied by proportionally increasing both $q_{\mathrm{sf}}$ and $p_{\mathrm{sf}}$. In order to obtain a constant loading ratio in the $Q P$ plane, the incremental surface loads $q_{\text {sf }}$ and $p_{\text {sf }}$ need to fulfil the following relationship

$$
\frac{\dot{q}_{\mathrm{sf}}}{\dot{p}_{\mathrm{sf}}}=\left(\frac{B+B_{\mathrm{nf}} \eta}{B_{\mathrm{nf}} B}\right)\left[\frac{B_{\mathrm{nf}}\left(B_{\mathrm{nf}}-B\right)}{\left(B_{\mathrm{nf}}-B\right)-\eta B_{\mathrm{nf}}}\right]
$$

where $\eta$ is the target obliquity $\left(\eta=\eta_{1}\right.$ along segment $\left.\mathrm{BB}^{\prime}\right)$. Although a radial path does not bring the system to failure, Fig. 14(b) still supports the suitability of the proposed ME model.

Multi-stage loading paths. The above examples helped when discussing possibilities and limitations of the ME model in dealing with loading paths including variations in boundary conditions (lateral surcharge) - previously referred to as configurational loading. In this subsection, two further applications are reported, concerning realistic multistage paths and the need for modelling the aforementioned configurational set-up. The latter has to do with capturing the effect of previous configurational loading on the SFI response (especially on the stiffness). Fig. 15(a) illustrates the following loading programme in the $Q P$ plane.

$0 \mathrm{~A}$ - uniform layer compression up to $q_{\mathrm{sf}}=p_{\mathrm{sf}}=15 \mathrm{kPa}$ $\mathrm{AA}^{\prime}$ - vertical loading on the foundation up to $q_{\mathrm{sf}}=270 \mathrm{kPa}, \dot{p}_{\mathrm{sf}}=0$; the $Q P$ inclination of the $\mathrm{AA}^{\prime}$ branch is $\left(B_{\mathrm{nf}}-B\right) / B_{\mathrm{nf}}$ as above

$\mathrm{A}^{\prime} \mathrm{B}$ - the lateral surcharge is increased up to $p_{\text {sf }}=60 \mathrm{kPa}$

$\mathrm{BB}^{\prime}$ - the foundation is reloaded and brought to failure.

The $Q P$ representation of the loading path highlights that lateral reloading actually brings the foundation further from shear failure ( $Q$ decreases along $\left.\mathrm{A}^{\prime} \mathrm{B}\right)$, while the following reloading $\mathrm{BB}^{\prime}$ is exactly parallel to the first deviatoric branch $\mathrm{AA}^{\prime}$. As is shown in Fig. 15(b), reloading from point B comes along with a stiffer load-settlement response, following the 


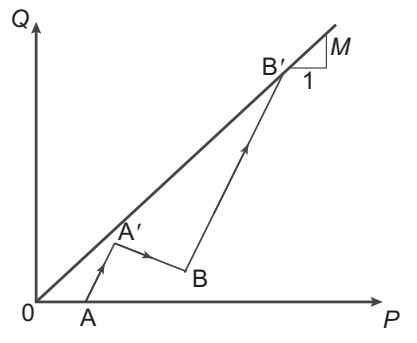

(a)

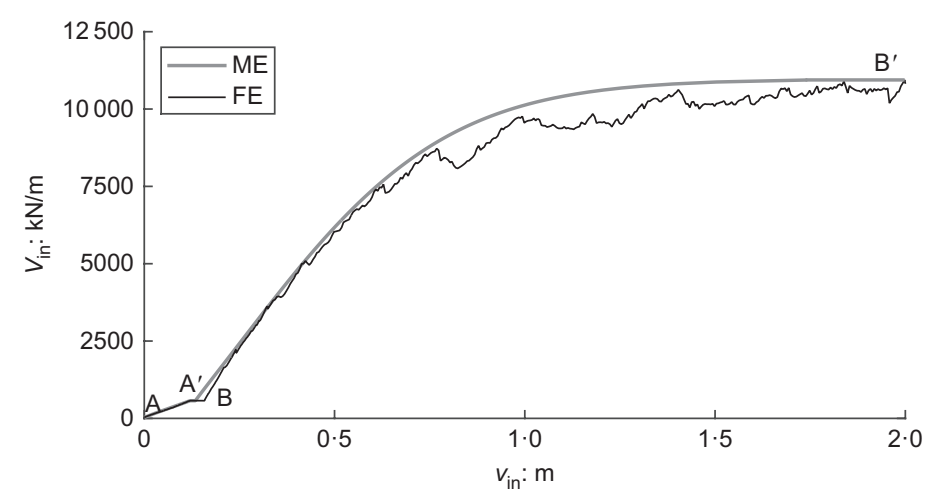

(b)

Fig. 15. Response to multi-stage loading including lateral surcharging: (a) qualitative $Q P$ loading path; (b) ME-FE comparison

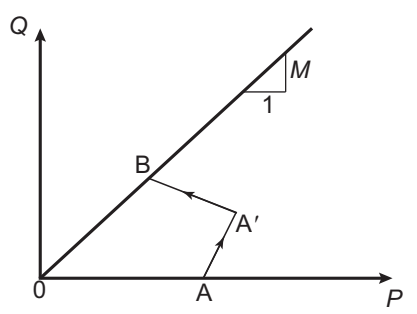

(a)

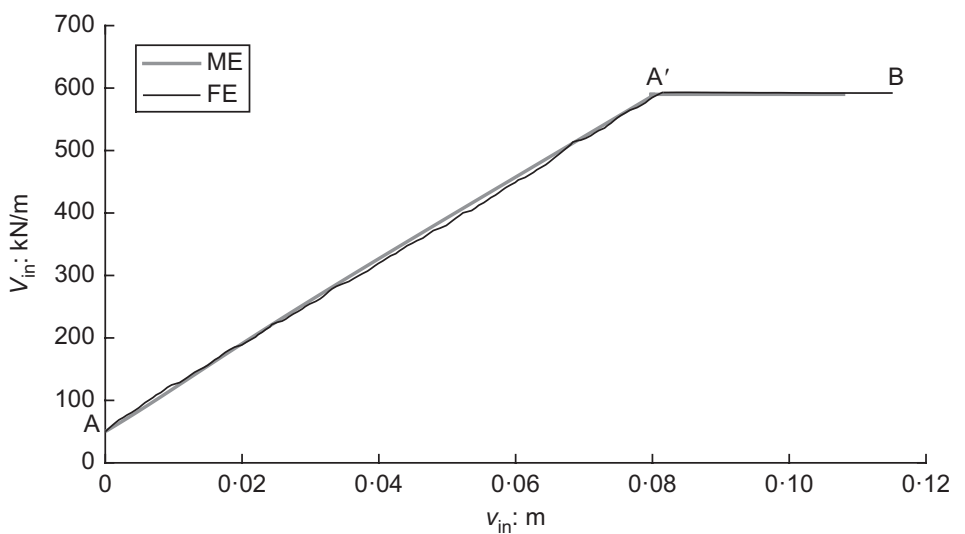

(b)

Fig. 16. Response to multi-stage loading including lateral unloading: (a) qualitative QP loading path; (b) ME-FE comparison

increase in confinement caused by lateral surcharging $\left(\dot{P}>0\right.$ along $\left.\mathrm{A}^{\prime} \mathrm{B}\right)$.

A different loading scenario is depicted in Fig. 16(a)

$0 \mathrm{~A}$ - uniform layer compression up to $q_{\mathrm{sf}}=p_{\mathrm{sf}}=25 \mathrm{kPa}$

$\mathrm{AA}^{\prime}$ - vertical loading on the foundation up to

$q_{\mathrm{sf}}=1600 \mathrm{kPa}, \dot{p}_{\mathrm{sf}}=0$

$\mathrm{A}^{\prime} \mathrm{B}-$ lateral unloading $\left(\dot{p}_{\mathrm{sf}}<0\right)$ up to failure.

In this case, lateral unloading ( $\mathrm{A}^{\prime} \mathrm{B}$ branch) results in a $Q P$ path characterised by a decrease in confinement and increasing $Q$, so that shear failure is achieved at point $\mathrm{B}$ - that is when the critical obliquity $Q / P=M$ is reached. Fig. 16(b) shows how good the ME model is at capturing the final vertical displacement at failure.

The results in Fig. 15 and Fig. 16 are further visualised in Fig. 17, in terms of loading ratio $\eta$ against the footing settlement, $v_{\text {in }}$. It can be readily observed that the same failure condition $(\eta=M$, generalised triaxial compression) is approached along two quite different loading paths. Interestingly, the shear failure produced by laterally unloading the soil surface is in fact associated with a continual loading of the foundation system, where loading is to be meant in the present generalised sense. The kind of failure illustrated in Fig. 16 could be, for instance, induced by a close excavation.

\section{NOVELTY AND ENGINEERING RELEVANCE}

This section collects some relevant remarks on why the proposed formulation goes beyond the existing approaches to ME modelling. This can be readily grasped by comparing the predictive capability of the new model and, for instance, of the well-known Nova \& Montrasio (NM) model (Nova \& Montrasio, 1991).

It should be noted first that, in the case of purely vertical loading, the NM model behaves somewhat 'onedimensionally', since it only allows the analysis of linear loading paths in the $Q-P$ plane with an inclination $\left(B_{\mathrm{nf}}-B\right) / B_{\mathrm{nf}}$ (see Fig. 18(a) and 'Definition of static and kinematic variables'). Conversely, any $Q-P$ path can be in principle simulated within the configurational framework proposed here, as is exemplified in Fig. 18(a)

(a) AB: vertical loading on the footing with constant lateral surcharge (also possible with the NM model)

(b) AC: failure induced by a reduction in lateral surcharge (excavation or nearby demolition of an existing building)

(c) $\mathrm{AD}$ and AE: mobilisation of reverse bearing capacity by reducing the direct load on the foundation (AE) or by severely increasing the lateral surcharge (AD) (the actual reverse failure behaviour - i.e. extension in the $Q<0$ half-plane - has not been investigated in this study)

(d) more complex combinations of the above loading programmes, such as those illustrated in Fig. 15 and Fig. 16.

Even though the NM model could somehow account for changes in lateral surcharge by adapting the bearing capacity (and other related parameters), there would still be no way to calculate the foundation settlement associated with lateral loading and/or unloading (see again Fig. 15 and Fig. 16 for comparison). As a future perspective, the new model will be 
rendered 'three/four-dimensional' when the soil weight and possible asymmetry in the lateral surcharge are considered as well.

Another relevant aspect concerns the stiffness performance for service limit state analysis. As explained by Nova \& Montrasio (1991), the NM response to vertical compression reduces to the following Butterfield's relationship (Butterfield, 1980)

$$
V_{\text {in }}=V_{\text {in }}^{\lim }\left[1-\mathrm{e}^{\left(R_{0} / V_{\text {in }}^{\lim }\right) v_{\text {in }}}\right]
$$

where, according to the terminology used throughout this paper, $V_{\mathrm{in}}^{\mathrm{lim}}$ is the vertical bearing capacity and $R_{0}$ is the initial tangent stiffness of the load-settlement curve $\left(R_{0}=\lim _{v_{\text {in }} \rightarrow 0} \mathrm{~d} V_{\text {in }} / \mathrm{d} v_{\text {in }}\right)$.

In the NM framework, $R_{0}$ - which is in fact a plastic stiffness since the very onset of loading - plays as a merely

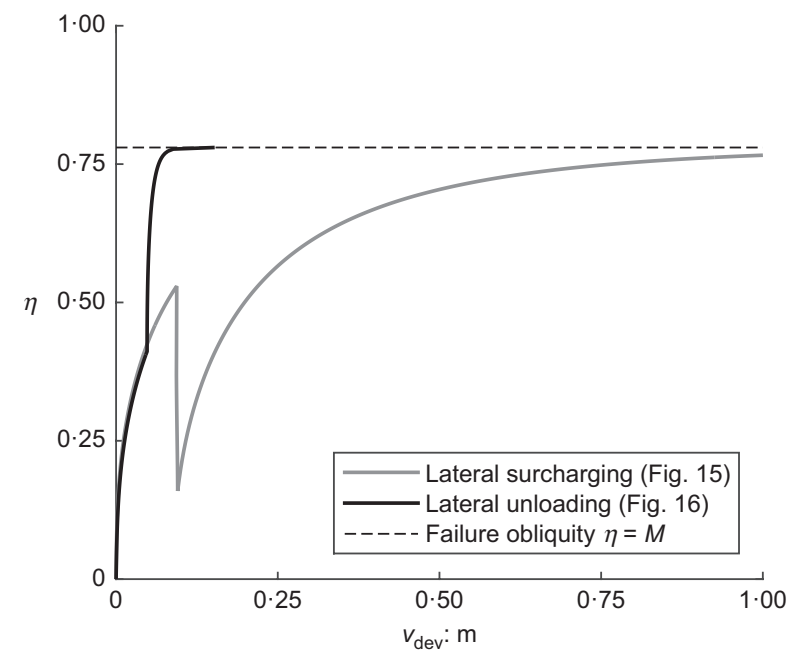

Fig. 17. Evolution of the loading ratio $\eta$ along the loading paths in Fig. 15 and Fig. 16 phenomenological input parameter, to be set at the beginning of the settlement analysis. Subsequently, Montrasio \& Nova (1997) found experimentally that the ratio $R_{0} B / V_{\text {in }}^{\lim }$ depends in general on the sand relative density, $D_{\mathrm{r}}$. In the same respect, the results presented in this work clearly show that configurational ME models can produce appropriate $R_{0}$ values as a spontaneous model output. Further, Fig. 18(b) illustrates the FE load-settlement curves for a strip footing $(B=2 \mathrm{~m})$ under vertical loading and different lateral

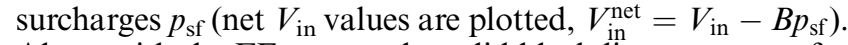
Along with the FE curves, the solid black lines represent for each case the initial tangent stiffness predicted by the ME model, to be compared with the elastic ME predictions at inhibited plasticity (marked lines). The quantitative difference between elastic and elastic-plastic predictions is self-apparent and has never been reconciled by the endless discussion on how to select suitable secant soil moduli for settlement predictions. The proposed ME approach can describe non-linear SFI since the onset of loading, as well as the influence of an evolving configuration.

\section{CONCLUSIONS}

A new ME framework has been proposed to model the response of vertically loaded footings in the presence of configurational loading and set-up (with this terminology meant as previously defined). As a first work on the subject, some simplifying assumptions have been introduced for the sake of simplicity, including: (a) plane-strain drained conditions; (b) fully dry or saturated soil deposit; and (c) weightless soil. Under these assumptions, the ME model has been formulated, calibrated and validated against FE results, revealing excellent accuracy in reproducing the effect of changes in lateral confinement, even under rather complex loading paths. The use of new static/kinematic foundation variables has brought up interesting analogies with wellknown modelling concepts in soil mechanics, then exploited for ME modelling purposes.

In the future, configuration-sensitive MEs may be employed in design to cope with different situations (varying

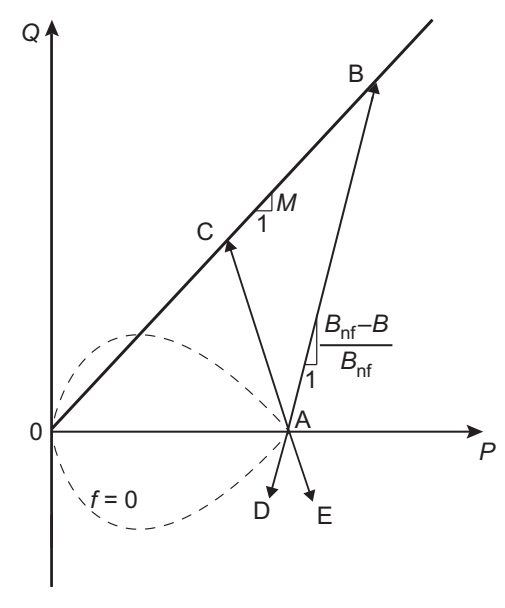

(a)

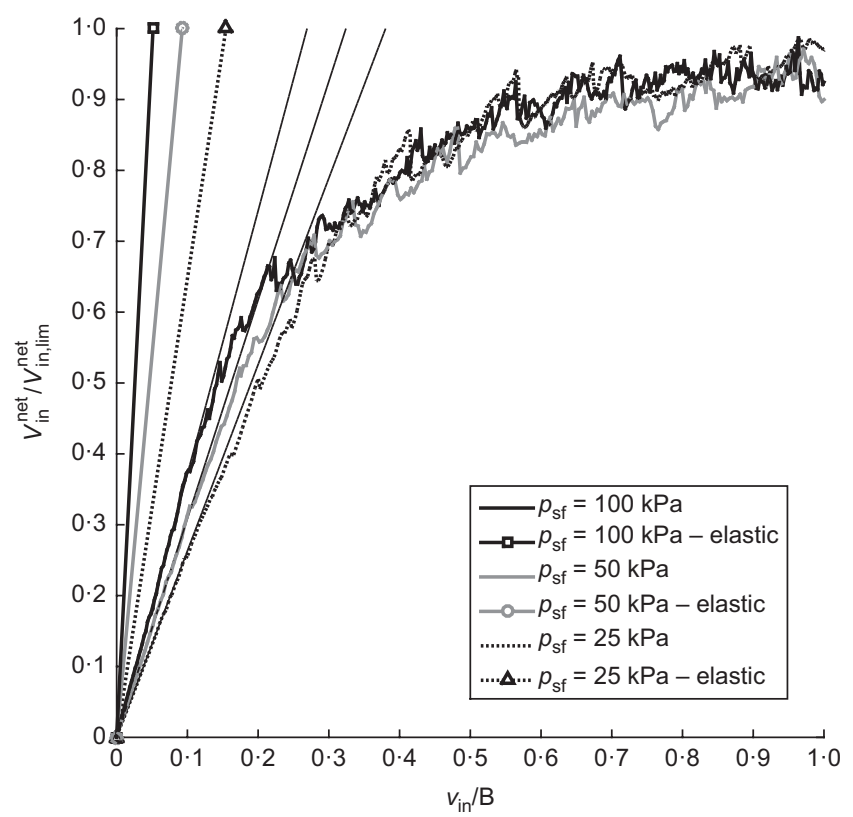

(b)

Fig. 18. (a) Qualitative illustration of relevant configuration loadings paths; (b) elastic against the elastic-plastic initial ME stiffness for a 2 m-wide footing at different lateral surcharge 
footing breadth, lateral surcharge and so on) with a single set of ME parameters.

It is finally worth noting that translating configurational factors (lateral surcharge and soil self-weight) into averaged force variables allows in principle the model to be combined with existing ME formulations for VHM loading. Additional work will be needed to understand how to deal with different, non-symmetric failure mechanisms, that possibly vary during the loading history.

\section{APPENDIX 1. CALIBRATION OF THE MMC MODEL}

This appendix summarises the main features of the MMC model (see Groen (1997) and Manie (2014) for details), as well as the calibration of MMC parameters for a Toyoura medium-dense sand (Zambelli, 2006). The cohesionless model formulation is expressed in terms of the usual isotropic and deviatoric stress invariants, $p^{\prime}$ and $q$ (Nova, 2013).

The MMC model features a non-linear elastic law, with a constant Poisson ratio $v$ and a pressure-dependent bulk modulus

$$
K_{\mathrm{t}}=K_{\mathrm{ref}}\left(p^{\prime} / p^{\prime} \text { ref }\right)^{1-n}
$$

where $n$ and $K_{\text {ref }}$ are constitutive parameters and the reference pressure $p_{\text {ref }}$ is such that $K_{\mathrm{t}}\left(p^{\prime}=p_{\text {ref }}^{\prime}\right)=K_{\text {ref. }}$ Apparently, the same pressure dependence characterises the other elastic moduli derived from $K_{\mathrm{t}}$, such as the oedometric Young's modulus in equation (21)

$$
E_{\mathrm{d}}=E_{\mathrm{d}, \mathrm{ref}}\left(\frac{p^{\prime}}{p_{\text {ref }}^{\prime}}\right)^{1-n} \quad \text { where } \quad E_{\mathrm{d}, \mathrm{ref}}=\frac{3(1-v)}{1+v} K_{\mathrm{ref}}
$$

The double-mechanism yielding is ruled by two distinct loci, $f_{1}=0$ (shear yielding) and $f_{2}=0$ (yielding cap for radial loading paths)

$$
\begin{aligned}
& f_{1}=\frac{q}{R_{1}(\theta)}-\frac{6 \sin \phi}{3-\sin \phi} p^{\prime}=0 \\
& f_{2}=p^{\prime 2}+\alpha\left(\frac{q}{R_{2}(\theta)}\right)^{2}-p_{\mathrm{c}}^{2}=0
\end{aligned}
$$

where $\alpha$ is a cap shape parameter (with no data on radial loading paths at different obliquities, the default value $\alpha=2 / 9$ has been set), and functions $R_{1}$ and $R_{2}$ determine the deviatoric $\pi$-section (i.e. dependence on the Lode angle $\theta$ ) of $f_{1}=0$ and $f_{2}=0$

$$
R_{1}(\theta)=\left(\frac{1-\beta_{1} \sin 3 \theta}{1-\beta_{1}}\right)^{b} \quad R_{2}(\theta)=1
$$

$\beta_{1}$ and $b$ in $R_{1}$ are constitutive parameters, while $R_{2}$ is assumed not to depend on $\theta$. The mobilised (yielding) friction angle $\phi$ in equation (27) evolves during monotonic loading as a function of the deviatoric equivalent plastic strain $\gamma_{\text {eff }}^{\mathrm{p}}$ (this hardening relationship can be user-defined in TNO Diana)

$$
\sin \phi=\sin \phi_{\mathrm{f}}-\left(\sin \phi_{0}-\sin \phi_{\mathrm{f}}\right) \mathrm{e}^{-a \gamma_{\mathrm{eff}}^{\mathrm{p}}}
$$

where $\phi_{0}$ and $\phi_{\mathrm{f}}$ are the mobilised friction angle at first yielding and failure, respectively, while $a$ is a material hardening parameter. The cap locus $f_{2}=0$ hardens through the hardening variable $p_{\mathrm{c}}$, in turn depending on the incremental volumetric plastic strain $\dot{\varepsilon}_{\mathrm{vol}}^{\mathrm{p}}$, the current void ratio $e$ and the hardening parameter $\delta$

$$
\frac{\dot{p}_{\mathrm{c}}}{p_{\mathrm{c}}}=\frac{1+e}{\delta} \dot{\varepsilon}_{\mathrm{vol}}^{\mathrm{p}}
$$

In the same way as for yielding, two plastic flow mechanisms are introduced through two different expressions for the plastic potential, $g_{1}$ and $g_{2}$

$$
g_{1}=q-\frac{6 \sin \psi}{3-\sin \psi} p^{\prime} \quad g_{2}=p^{\prime 2}+\alpha q^{2}-\left(p_{\mathrm{c}}^{\mathrm{g}}\right)^{2}
$$

having a circular deviatoric $\pi$-section (no $\theta$-dependence) and with $g_{2}=f_{2}$. The dilatancy angle $\psi$ in $g_{1}$ evolves along with $\phi$ according to the well-known Rowe's relationship (Rowe, 1962)

$$
\sin \psi=\frac{\sin \phi-\sin \phi_{\mathrm{cv}}}{1-\sin \phi \sin \phi_{\mathrm{cv}}}
$$

where the constant volume friction angle $\phi_{\mathrm{cv}}$ is associated with the maximum dilatancy $\psi_{\max }=\arcsin \left[\left(\sin \phi_{\mathrm{f}}-\sin \phi_{\mathrm{cv}}\right) /\left(1-\sin \phi_{\mathrm{f}} \sin \phi_{\mathrm{cv}}\right)\right]$ (Fig. 19(b)).

The MMC parameters calibrated for the Toyoura sand tested by Zambelli (2006) are listed in Table 2, while an initial void ratio $e_{0}=0.67$ has been determined from the initial relative density in the experimental tests. The satisfactory performance of the MMC model is illustrated in Fig. 19 with respect to triaxial compression/ extension tests at initial confinement $p_{0}^{\prime}=100 \mathrm{kPa}$, as well as under isotropic compression. For the sake of brevity, only triaxial tests at $p_{0}^{\prime}=100 \mathrm{kPa}$ are shown, but the model has been verified to perform well also for $p_{0}^{\prime}=200$ and $300 \mathrm{kPa}$.

\section{APPENDIX 2. ISOTROPIC COMPLIANCE}

This appendix briefly recalls how the foundational isotropic compliance $C_{\mathrm{PP}}=\mathrm{d} \varepsilon_{\mathrm{vol}} / \mathrm{d} P$ can be analytically derived. Both cases of non-linear elastic (equation (26)) and MMC elastic-plastic soil are considered.

Under generalised isotropic loading, the soil layer undergoes an oedometric compression. Accordingly, $v_{\mathrm{vol}}=v_{\text {in }}$ and the following $C_{\mathrm{PP}}$ expression results

$$
\begin{aligned}
v_{\mathrm{vol}} & =v_{\mathrm{in}}=\int_{0}^{H}\left(\int_{0}^{P} \frac{\mathrm{d} \varepsilon_{z}}{\mathrm{~d} P^{\prime}} \mathrm{d} P^{\prime}\right) \mathrm{d} z \\
\Rightarrow C_{\mathrm{PP}} & =\frac{\mathrm{d} v_{\mathrm{vol}}}{\mathrm{d} P}=\int_{0}^{H} \frac{\mathrm{d} \varepsilon_{z}}{\mathrm{~d} P} \mathrm{~d} z=H \frac{\mathrm{d} \varepsilon_{z}}{\mathrm{~d} P}
\end{aligned}
$$

where $\bar{\sigma}_{z}=P / B_{\mathrm{nf}}$ (equation (7)) and the geometrical factor $H$ spontaneously arises.

\section{Non-linear elastic case}

The (non-linear) elastic isotropic compliance can be easily obtained from the incremental oedometric relationship between vertical stress and strain (see equation (26))

$$
\mathrm{d} \varepsilon_{z}=\frac{1}{E_{\mathrm{d}, \text { ref }}\left(p^{\prime} / p_{\text {ref }}\right)^{1-n}} \mathrm{~d} \bar{\sigma}_{z}
$$

where $p^{\prime}=\left(1+2 k_{0}^{\mathrm{e}} / 3\right) \bar{\sigma}_{z}$ and $k_{0}^{\mathrm{e}}=v /(1-v)$. The elastic isotropic compliance is finally obtained by combining equations (33) and (34) and the definition $\bar{\sigma}_{z}=P / B_{\mathrm{nf}}$

$$
\begin{aligned}
C_{\mathrm{PP}}^{\mathrm{e}}=H \frac{\mathrm{d} \varepsilon_{z}}{\mathrm{~d} P} & =H \frac{1}{E_{\mathrm{d}, \text { ref }}\left(p^{\prime} / p_{\mathrm{ref}}\right)^{1-\mathrm{n}}} \frac{\mathrm{d} \bar{\sigma}_{z}}{\mathrm{~d} P} \\
& =\frac{1}{E_{\mathrm{d}, \text { ref }}} \frac{H}{\left(B_{\mathrm{nf}}\right)^{n}}\left(\frac{1+2 k_{0}^{\mathrm{e}}}{3 p_{\text {ref }}} P\right)^{n-1}
\end{aligned}
$$

\section{Elastic-plastic case}

The isotropic term in the hardening rule, equation (18), stands for the plastic contribution to the global (elastic-plastic) isotropic compliance

$$
\begin{aligned}
C_{\mathrm{PP}}=C_{\mathrm{PP}}^{\mathrm{e}}+C_{\mathrm{PP}}^{\mathrm{p}} & =H \frac{\mathrm{d} \varepsilon_{z}}{\mathrm{~d} P}=H \frac{\mathrm{d} \varepsilon_{\mathrm{vol}}}{\mathrm{d} P}=H \frac{\mathrm{d} \varepsilon_{\mathrm{vol}}^{\mathrm{e}}}{\mathrm{d} P}+H \frac{\mathrm{d} \varepsilon_{\mathrm{vol}}^{\mathrm{p}}}{\mathrm{d} P} \\
& =H \frac{\mathrm{d} \varepsilon_{\mathrm{vol}}^{\mathrm{e}}}{\mathrm{d} P}+H \frac{\mathrm{d}}{\mathrm{d} P}\left(\frac{\delta}{1+e_{0}} \frac{\mathrm{d} \bar{\sigma}_{z}}{\bar{\sigma}_{z}}\right)
\end{aligned}
$$

where the plastic term has been derived from the MMC hardening rule, equation (30), under the (quite accurate) assumption $\mathrm{d} \varepsilon_{z}^{\mathrm{p}}=\mathrm{d} \varepsilon_{\mathrm{vol}}^{\mathrm{p}}$, while $\mathrm{d} \bar{\sigma}_{z} / \bar{\sigma}_{z}=\mathrm{d} p^{\prime} / p^{\prime}$ as long as horizontal soil stresses vary proportionally to the vertical component (radial loading assumption). Finally, since $\mathrm{d} \bar{\sigma}_{z} / \bar{\sigma}_{z}=\mathrm{d} P / P$, the following good estimations for $C_{\mathrm{PP}}^{\mathrm{p}}$ and the hardening ME parameter $C_{\mathrm{p}}$ result

$$
C_{\mathrm{PP}}^{\mathrm{p}} \approx \frac{H}{P} \frac{\delta}{1+e_{0}}=\frac{H C_{\mathrm{p}}}{P} \Rightarrow C_{\mathrm{p}} \approx \frac{\delta}{1+e_{0}}
$$

where the approximation $e=e_{0}$ is kept. 


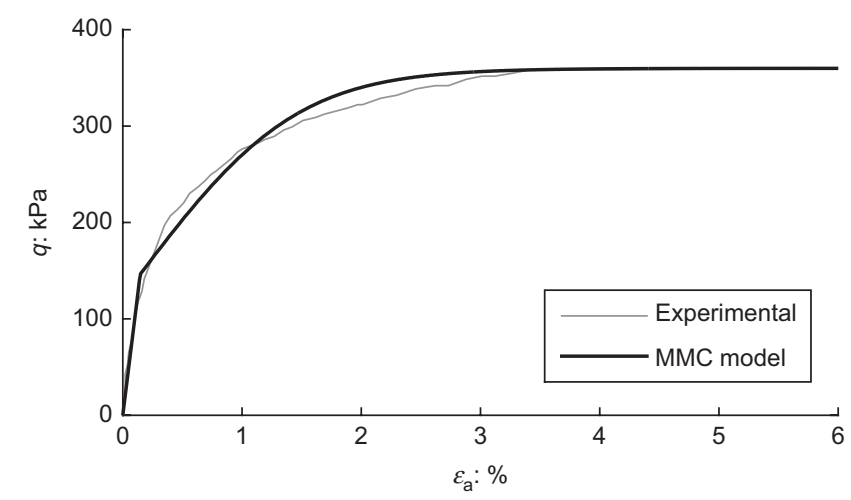

(a)

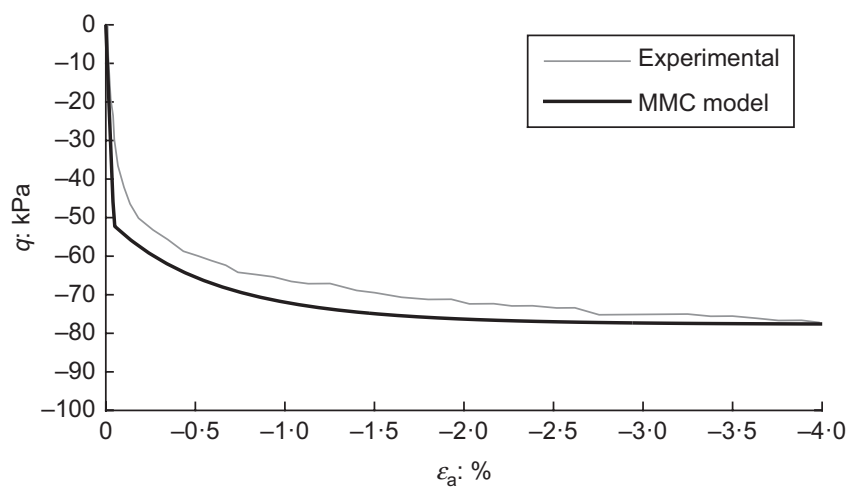

(c)

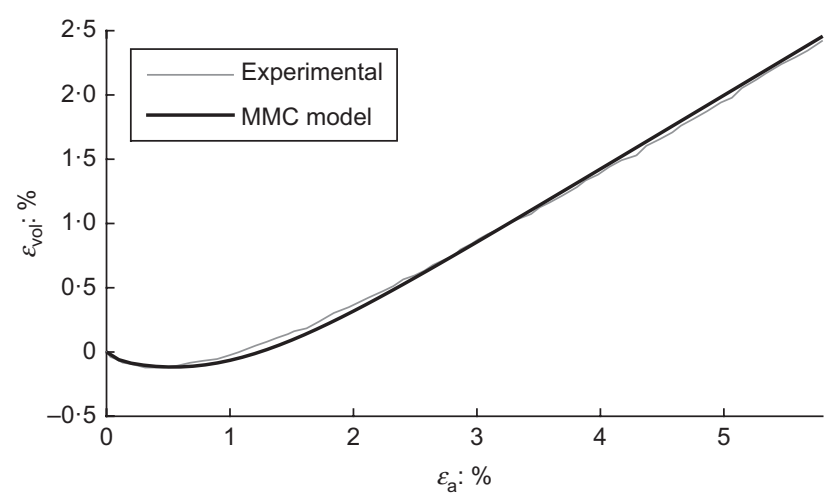

(b)

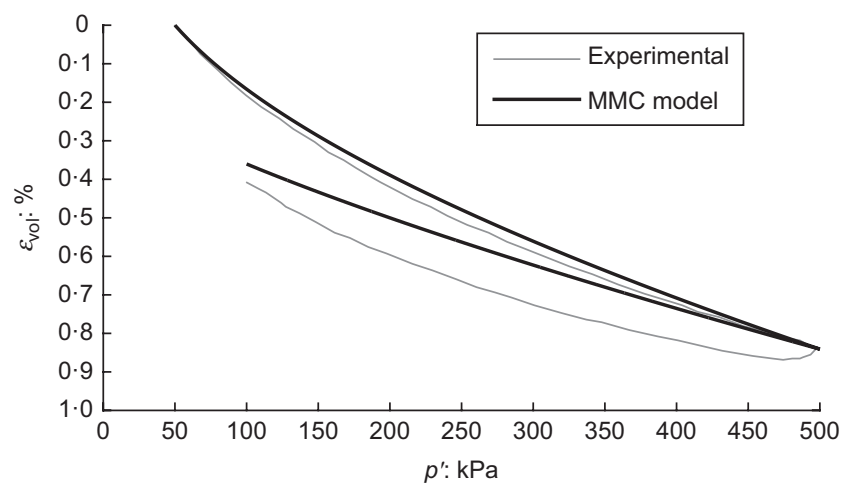

(d)

Fig. 19. MMC performance for a medium-dense Toyoura sand; triaxial compression at $p_{0}^{\prime}=100 \mathrm{kPa}$ : (a) stress-strain curve and (b) volumetric response; (c) triaxial extension at $p_{0}^{\prime}=100 \mathrm{kPa}$; (d) isotropic compression

Table 2. MMC soil parameters

\begin{tabular}{l|c|c|c|c|c|c|c|c|c|c|c}
\hline$K_{\text {ref }}: \mathrm{MPa}$ & $p_{\text {ref }}^{\prime}: \mathrm{kPa}$ & $n$ & $v$ & $\phi_{0}: \operatorname{deg}$ & $\phi_{\mathrm{f}}: \operatorname{deg}$ & $\alpha$ & $\beta_{1}$ & $b$ & $a$ & $\delta$ & $\psi_{\text {max }}: \operatorname{deg}$ \\
\hline 65 & 100 & 0.75 & 0.2 & 25 & 40 & 0.222 & 0.75 & -0.229 & 160 & 0.002 & 12 \\
\hline
\end{tabular}

\section{ACKNOWLEDGEMENTS}

The authors wish to thank Mr M. Culotta for contributing to this research during his $\mathrm{MSc}$ project at Politecnico di Milano, as well as Dr Fabio Tradigo (Arup) for the valuable support to M. Culotta's work. The assistance and the code license provided by the TNO Diana team in Delft (the Netherlands) are also gratefully acknowledged.

\section{NOTATION}

a plastic soil parameter in MMC constitutive model

$B$ foundation breadth

$B_{\mathrm{nf}} \quad$ horizontal size of near-field domain

$b$ plastic soil parameter in MMC constitutive model

$C_{\mathrm{p}}$ constitutive parameter in ME hardening rule

$C_{\mathrm{PP}}$ isotropic compliance in ME model

$C_{\mathrm{PP}}^{\mathrm{e}}, C_{\mathrm{QQ}}^{\mathrm{e}}, C_{\mathrm{PQ}}^{\mathrm{e}}, C_{\mathrm{QP}}^{\mathrm{e}} \quad$ elastic compliances in $\mathrm{ME}$ model

$C_{\mathrm{PP}}^{\mathrm{p}} \quad$ isotropic plastic compliance in ME model

$c$ soil cohesion

$D \quad$ ME dilatancy at failure

d ME dilatancy

$E_{\mathrm{d}, \text { ref }}$ elastic soil parameter in MMC constitutive model

$e_{0} \quad$ initial soil void ratio

$F$ failure function of ME model

$f$ yield locus of ME model $f_{1}, f_{2}$ yield functions in MMC constitutive model $g$ plastic potential of ME model

$g_{1}, g_{2}$ plastic potential functions in MMC constitutive model

$H$ thickness of soil stratum

$H_{\mathrm{nf}}$ vertical size of near-field domain

$H_{\mathrm{w}} \quad$ depth of water table

$K_{\text {ref }}$ elastic soil parameter in MMC constitutive model

$K_{\mathrm{t}} \quad$ soil pressure-dependent bulk modulus

$k_{0}^{\mathrm{e}} \quad$ incremental elastic at-rest earth pressure coefficient

$M$ slope of failure locus

$m$ constitutive parameter in ME yield function $N_{\mathrm{c}}, N_{\mathrm{q}}, N_{\gamma} \quad$ bearing capacity factors

$\tilde{N}_{\mathrm{c}}, \tilde{N}_{\mathrm{q}}, \tilde{N}_{\gamma}$ generalised bearing capacity factors

$n$ plastic soil parameter in MMC constitutive model

$P$ generalised isotropic load

$P_{\mathrm{c}} \quad$ ME hardening variable

$P_{\mathrm{g}}$ dummy variable in ME plastic potential

$p^{\prime} \quad$ effective mean stress

$p_{\text {ref }} \quad$ elastic soil parameter

$p_{\text {sf }}$ lateral surcharge

$Q$ generalised deviatoric load

$Q_{0} \quad$ ME variable in yield function

$Q_{0 \mathrm{~g}} \quad$ ME variable in plastic potential function

$q_{\mathrm{sf}}$ vertical pressure on foundation

$R_{1}, R_{2}$ plastic parameters in MMC constitutive model 
$V_{\text {in }} \quad$ vertical load on foundation

$V_{\text {out }}$ lateral vertical load

$v_{\mathrm{dev}}$ generalised deviatoric displacement

$v_{\text {in }}$ foundation settlement

$v_{\text {out }}$ vertical displacement in near-field domain outside the foundation

$v_{\mathrm{vol}}$ generalised volumetric displacement

$v_{\Omega} \quad$ ME kinematic variable generated by soil unit weight

$x$ horizontal coordinate

$z$ vertical coordinate

$\alpha$ plastic soil parameter in MMC constitutive model

$\alpha_{\mathrm{g}} \quad$ ME variable depending on $M, \beta_{\mathrm{g}}, \gamma_{\mathrm{g}}$ and $\rho_{\mathrm{f}}$

$\beta, \gamma \quad$ ME parameters in yield function

$\beta_{1}$ plastic soil parameter in MMC constitutive model

$\beta_{\mathrm{g}}, \gamma_{\mathrm{g}} \quad$ ME shape parameters in plastic potential function

$\delta \quad$ soil hardening parameter

$\delta W^{\mathrm{e}}$ total elastic work input

$\delta W_{\mathrm{nf}}^{\mathrm{e}} \quad$ total elastic work input in near-field domain

$\delta W_{\text {nf }}$ external work input in near-field domain

$\delta W_{\text {nf }}^{\text {sf }} \quad$ external work input generated by body forces in near-field domain

$\delta W_{\mathrm{nf}}^{\mathrm{sf}} \quad$ external work input generated by surface loads in near-field domain

$\delta W^{\mathrm{p}}$ total plastic work

$\delta W_{\mathrm{nf}}^{\mathrm{p}}$ total plastic work in near-field domain

$\delta v \quad$ virtual variation of vertical displacement field

$\epsilon_{\mathrm{vol}}^{\mathrm{p}} \quad$ volumetric plastic strain

$\stackrel{\text { vol }}{\Gamma}$ ME static variable associated with soil unit weight

$\gamma \quad$ soil unit weight

$\gamma_{\text {eff }}^{\mathrm{p}} \quad$ equivalent plastic strain

$\eta$ generalised loading ratio

$\theta$ Lode angle

$v$ soil Poisson ratio

$\rho_{\mathrm{f}} \quad$ ME variable depending on $\beta_{\mathrm{g}}, \gamma_{\mathrm{g}}, D$ and $M$

$\sigma_{\mathrm{a}} \quad$ axial stress

$\sigma_{\mathrm{c}}$ confining pressure

$\sigma_{\mathrm{r}}$ radial stress

$\begin{array}{ll}\sigma_{\mathrm{r}} & \text { soil friction angle }\end{array}$

$\phi^{*} \quad$ plane strain soil friction angle

$\phi_{\mathrm{f}}$ soil friction at failure

$\phi_{0} \quad$ soil friction angle at first yielding

$\psi$ soil dilatancy angle

$\psi_{\max }$ maximum dilatancy angle

$\Omega_{\mathrm{nf}}$ near-field domain

\section{REFERENCES}

Bienen, B., Byrne, B. W., Houlsby, G. T. \& Cassidy, M. J. (2006). Investigating six-degree-of-freedom loading of shallow foundations on sand. Géotechnique 56, No. 6, 367-379, http://dx.doi. org/10.1680/geot.2006.56.6.367.

Bowles, J. E. (1996). Foundation analysis and design. New York, NY, USA: McGraw-Hill.

Butterfield, R. (1980). A simple analysis of the load capacity of rigid footings on granular materials. In Journée de Géotechnique, pp. 128-134. Lyon, France: ENTPE.

Butterfield, R. \& Ticof, J. (1979). Design parameters for granular soils. In Proceedings of the 7th European conference on soil mechanics and foundation engineering, Brighton, vol. 4 , pp. 259-261. London, UK: British Geotechnical Society.

Byrne, B. (2013). Combined loading of shallow foundations: application to offshore wind turbines. In Proceedings of the 15th European conference on soil mechanics and geotechnical engineering: geotechnics of hard soils-weak rocks (eds A. Anagnostopoulos, M. Pachakis and C. Tsatsanifos), p. 336. Amsterdam, the Netherlands: IOS Press.

Byrne, B. \& Houlsby, G. (2003). Foundations for offshore wind turbines. Phil. Trans. R. Soc. London A: Math., Phys. Engng Sci. 361, No. 1813, 2909-2930.

Calvetti, F., di Prisco, C. \& Nova, R. (2004). Experimental and numerical analysis of soil-pipe interaction. J. Geotech. Geoenviron. Engng 130, No. 12, 1292-1299.

Cassidy, M. J., Randolph, M. F. \& Byrne, B. W. (2006). A plasticity model describing caisson behaviour in clay. Appl. Ocean Res. 28, No. 5, 345-358.

Chatzigogos, C. T., Pecker, A. \& Salencon, J. (2009). Macroelement modeling of shallow foundations. Soil Dynam. Earthquake Engng 29, No. 5, 765-781.

Chen, W. F. (2013). Limit analysis and soil plasticity. Amsterdam, the Netherlands: Elsevier.

Cheuk, C. \& White, D. (2011). Modelling the dynamic embedment of seabed pipelines. Géotechnique 61, No. 1, 39-57, http://dx.doi. org/10.1680/geot.8.P.148.

Cocchetti, G., di Prisco, C. \& Galli, A. (2008). Soil-pipeline interaction along active fault systems. Int. J. Offshore Polar Engng 18, No. 3, 211-219.

Cocchetti, G., di Prisco, C. \& Galli, A. (2009a). Soil-pipeline interaction along unstable slopes: a coupled three-dimensional approach. Part 2: numerical analyses. Can. Geotech. J. 46 , No. 11, 1305-1321.

Cocchetti, G., di Prisco, C., Galli, A. \& Nova, R. (2009b). Soil-pipeline interaction along unstable slopes: a coupled three-dimensional approach. Part 1: theoretical formulation. Can. Geotech. J. 46, No. 11, 1289-1304.

Crémer, C., Pecker, A. \& Davenne, L. (2001). Cyclic macro-element for soil-structure interaction: material and geometrical nonlinearities. Int. J. Numer. Analyt. Methods Geomech. 25, No. 13, $1257-1284$

Crémer, C., Pecker, A. \& Davenne, L. (2002). Modelling of nonlinear dynamic behaviour of a shallow strip foundation with macro-element. J. Earthquake Engng 6, No. 2, 175-211.

Dattola, G. (2011). A numerical and theoretical analysis of compaction banding in cemented porous geomaterials. $\mathrm{PhD}$ thesis, Politecnico di Milano, Milan, Italy.

Davis, E. H. (1968). Theories of plasticity and the failure of soil masses. In Soil Mechanics (Selected Topics) (ed. I. K. Lee), ch. 6, pp. 341-380. London, UK: Butterworths.

De Borst, R. \& Vermeer, P. A. (1984). Possibilites and limitations of finite elements for limit analysis. Géotechnique 34, No. 2, 199-210, http://dx.doi.org/10.1680/geot.1984.34.2.199.

di Prisco, C. \& Pisanò, F. (2011a). An exercise on slope stability and perfect elastoplasticity. Géotechnique 61, No. 11, 923-934, http://dx.doi.org/10.1680/geot.9.P.040.

di Prisco, C. \& Pisanò, F. (2011b). Seismic response of rigid shallow footings. Eur. J. Environ. Civ. Engng 15, No. sup1, 185-221.

di Prisco, C. \& Vecchiotti, M. (2006). A rheological model for the description of boulder impacts on granular strata. Géotechnique 56, No. 7, 469-482, http://dx.doi.org/10. 1680/geot.2006.56.7.469.

di Prisco, C., Nova, R. \& Corengia, A. (2004). A model for landslide-pipe interaction analysis. Soils Found. 44, No. 3, 1-12.

di Prisco, C., Pastor, M. \& Pisanò, F. (2012). Shear wave propagation along infinite slopes: a theoretically based numerical study. Int. J. Numer. Analyt. Methods Geomech. 36, No. 5, 619-642.

Drescher, A. \& Detournay, E. (1993). Limit load in translational failure mechanisms for associative and non-associative materials. Géotechnique 43, No. 3, 443-456, http://dx.doi. org/10.1680/geot.1993.43.3.443.

Erickson, H. L. \& Drescher, A. (2002). Bearing capacity of circular footings. J. Geotech. Geoenviron. Engng 128, No. 1, 38-43.

Figini, R., Paolucci, R. \& Chatzigogos, C. T. (2012). A macroelement model for non-linear soil-shallow foundation-structure interaction under seismic loads: theoretical development and experimental validation on large scale tests. Earthquake Engng Struct. Dynam. 41, No. 3, 475-493.

Foglia, A., Govoni, L., Gottardi, G. \& Ibsen, L. B. (2014). Investigations on macro-element modelling of bucket foundations for offshore wind turbines. Aalborg, Denmark: Department of Civil Engineering, Aalborg University.

Frydman, S. \& Burd, H. J. (1997). Numerical studies of bearingcapacity factor $\mathrm{N} \gamma$. J. Geotech. Geoenviron. Engng 123, No. 1, $20-29$.

Gottardi, G., Houlsby, G. T. \& Butterfield, R. (1999). Plastic response of circular footings on sand under general planar 
loading. Géotechnique 49, No. 4, 453-469, http://dx.doi.org/ 10.1680/geot.1999.49.4.453.

Grange, S., Kotronis, P. \& Mazars, J. (2008). A macro-element for a circular foundation to simulate $3 \mathrm{~d}$ soil-structure interaction. Int. J. Numer. Analyt. Methods Geomech. 32, No. 10, $1205-1227$.

Grange, S., Kotronis, P. \& Mazars, J. (2009). A macro-element to simulate dynamic soil-structure interaction. Engng Structs 31, No. 12, 3034-3046.

Grange, S., Botrugno, L., Kotronis, P. \& Tamagnini, C. (2011). The effects of soil-structure interaction on a reinforced concrete viaduct. Earthquake Engng Structl Dynam. 40, No. 1, 93-105.

Groen, A. E. (1997). Three-dimensional elasto-plastic analysis of soils. Delft, the Netherlands: Delft University of Technology.

Houlsby, G. T. \& Cassidy, M. J. (2002). A plasticity model for the behaviour of footings on sand under combined loading. Géotechnique 52, No. 2, 117-129, http://dx.doi.org/10.1680/ geot.2002.52.2.117.

Li, Z., Kotronis, P., Escoffier, S. \& Tamagnini, C. (2015). A hypoplastic macroelement for single vertical piles in sand subject to three-dimensional loading conditions. Acta Geotechnica 11, No. 2, 373-390.

Loukidis, D. \& Salgado, R. (2009). Bearing capacity of strip and circular footings in sand using finite elements. Comput. Geotech. 36, No. 5, 871-879.

Manie, J. (2014). TNO Diana bv. user's manual - release 9.5. Delft, the Netherlands: TNO Diana.

Manoharan, N. \& Dasgupta, S. (1995). Bearing capacity of surface footings by finite elements. Comput. Structs 54, No. 4, $563-586$.

Marchi, M., Butterfield, R., Gottardi, G. \& Lancellotta, R. (2011). Stability and strength analysis of leaning towers. Géotechnique 61, No. 12, 1069-1079, http://dx.doi.org/10. 1680/geot.9.P.054.

Marti, J. \& Cundall, P. (1982). Mixed discretization procedure for accurate modelling of plastic collapse. Int. J. Numer. Analyt. Methods Geomech. 6, No. 1, 129-139.

Martin, C. M. \& Houlsby, G. T. (2001). Combined loading of spudcan foundations on clay: numerical modelling. Géotechnique 51, No. 8, 687-699, http://dx.doi.org/10. 1680/geot.2001.51.8.687.

Montrasio, L. \& Nova, R. (1997). Settlements of shallow foundations on sand: geometrical effects. Géotechnique 47, No. 1, 49-60, http://dx.doi.org/10.1680/geot.1997.47.1.49.

Muir Wood, D. (2004). Geotechnical modelling. Abingdon, UK: Spon Press.

Nagtegaal, J. C., Parks, D. M. \& Rice, J. R. (1974). On numerically accurate finite element solutions in the fully plastic range. Comput. Methods Appl. Mech. Engng 4, No. 2, 153-177.

Nguyen-Sy, L. (2005). The theoretical modelling of circular shallow foundation for offshore wind turbines. $\mathrm{PhD}$ thesis, University of Oxford, Oxford, UK.

Nova, R. (1977). On the hardening of soils. Archs Mech. 29, No. 3, 445-458.

Nova, R. (2013). Soil mechanics. Hoboken, NJ, USA: John Wiley \& Sons.

Nova, R. \& Montrasio, L. (1991). Settlements of shallow foundations on sand. Géotechnique 41, No. 2, 243-256, http://dx.doi. org/10.1680/geot.1991.41.2.243.

Paolucci, R. (1997). Simplified evaluation of earthquake-induced permanent displacements of shallow foundations. J. Earthquake Engng 1, No. 03, 563-579.
Pisanò, F., di Prisco, C. \& Lancellotta, R. (2014). Soil-foundation modelling in laterally loaded historical towers. Géotechnique 64, No. 1, 1-15, http://dx.doi.org/10.1680/geot.12.P.141.

Roscoe, K. \& Schofield, A. (1956). The stability of short pier foundations on sand, discussion. Br. Welding J. 3, No. 8, 343-354.

Rowe, P. W. (1962). The stress-dilatancy relation for static equilibrium of an assembly of particles in contact. Proc. R. Soc. London A: Math., Phys. Engng Sci., vol. 269, pp. $500-527$.

Salciarini, D. \& Tamagnini, C. (2009). A hypoplastic macroelement model for shallow foundations under monotonic and cyclic loads. Acta Geotechnica 4, No. 3, 163-176.

Salciarini, D., Bienen, B. \& Tamagnini, C. (2011). A hypoplastic macroelement for shallow foundations subject to six-dimensional loading paths. In COM.Geo 2011: proceedings of the 2nd international conference on computing for geospatial research and applications (eds G. N. Pande and S. Pietruszczak), pp. 721-733. Washington, DC, USA: Association for Computing Machinery.

Schotmann, G. J. M. (1989). The effects of displacements on the stability of jackup spudcan foundations. Proceedings of the offshore technology conference, Houston, TX, USA, paper OTC 6026.

Schotmann, G. J. M. \& Stork, F. G. (1987). Pipe-soil interaction: a model for laterally loaded pipelines in clay. Proceedings of the offshore technology conference.

Shirato, M., Paolucci, R., Kouno, T., Nakatani, S., Fukui, J., Nova, R. \& di Prisco, C. (2008). Numerical simulation of model tests of pier-shallow foundation systems subjected to earthquake loads using an elasto-uplift-plastic macro element. Soils Found. 48, No. 5, 693-711.

Sloan, S. W. \& Randolph, M. F. (1982). Numerical prediction of collapse loads using finite element methods. Int. J. Numer. Analyt. Methods Geomech. 6, No. 1, 47-76.

Tamagnini, C., Salciarini, D. \& Ragni, R. (2013). Implementation of 6-dof hypoplastic macroelement in a finite element code. In COM. Geo 2012: proceedings of the 3rd international conference on computing for geospatial research and applications (eds G. N. Pande and S. Pietruszczak), pp. 60-71. Washington, DC, USA: Association for Computing Machinery.

Tian, Y. \& Cassidy, M. J. (2008). Modeling of pipe-soil interaction and its application in numerical simulation. Int. J. Geomech. $\mathbf{8}$, No. 4, 213-229.

Vermeer, P. A. (1990). The orientation of shear bands in biaxial tests. Géotechnique 40, No. 2, 223-236, http://dx.doi.org/10.1680/ geot.1990.40.2.223.

Yin, J., Wang, Y. \& Selvadurai, A. (2001). Influence of nonassociativity on the bearing capacity of a strip footing. J. Geotech. Geoenviron. Engng 127, No. 11, 985-989.

Zambelli, C. (2006). Experimental and theoretical analysis of the mechanical behaviour of cohesionless soils under cyclic-dynamic loading. $\mathrm{PhD}$ thesis, Politecnico di Milano, Milan, Italy.

Zhang, J., Stewart, D. P. \& Randolph, M. F. (2002). Modeling of shallowly embedded offshore pipelines in calcareous sand. J. Geotech. Geoenviron. Engng 128, No. 5, 363-371.

Zhang, Y., Cassidy, M. J. \& Bienen, B. (2014). A plasticity model for spudcan foundations in soft clay. Can. Geotech. J. 51, No. 6, 629-646.

Zienkiewicz, O. \& Taylor, R. (2000). The finite element method. Vol. 1: Its basis and fundamentals, 5th edn. Oxford, UK: Butterworth-Heinemann. 